Review

\title{
Enzymology of Alternative Carbohydrate Catabolic Pathways
}

\author{
Dominik Kopp ${ }^{1}$, Peter L. Bergquist ${ }^{1,2}$ and Anwar Sunna ${ }^{1,3, *(\mathbb{C}}$ \\ 1 Department of Molecular Sciences, Macquarie University, Sydney 2109, Australia; \\ dominik.kopp@mq.edu.au (D.K.); peter.bergquist@mq.edu.au (P.L.B.) \\ 2 Department of Molecular Medicine \& Pathology, The University of Auckland, Auckland 1142, New Zealand \\ 3 Biomolecular Discovery Research Centre, Macquarie University, Sydney 2109, Australia \\ * Correspondence: anwar.sunna@mq.edu.au; Tel.: +61-2-9850-4220
}

Received: 11 September 2020; Accepted: 19 October 2020; Published: 23 October 2020

\begin{abstract}
The Embden-Meyerhof-Parnas (EMP) and Entner-Doudoroff (ED) pathways are considered the most abundant catabolic pathways found in microorganisms, and ED enzymes have been shown to also be widespread in cyanobacteria, algae and plants. In a large number of organisms, especially common strains used in molecular biology, these pathways account for the catabolism of glucose. The existence of pathways for other carbohydrates that are relevant to biomass utilization has been recognized as new strains have been characterized among thermophilic bacteria and Archaea that are able to transform simple polysaccharides from biomass to more complex and potentially valuable precursors for industrial microbiology. Many of the variants of the ED pathway have the key dehydratase enzyme involved in the oxidation of sugar derived from different families such as the enolase, IlvD/EDD and xylose-isomerase-like superfamilies. There are the variations in structure of proteins that have the same specificity and generally greater-than-expected substrate promiscuity. Typical biomass lignocellulose has an abundance of xylan, and four different pathways have been described, which include the Weimberg and Dahms pathways initially oxidizing xylose to xylono-gamma-lactone/xylonic acid, as well as the major xylose isomerase pathway. The recent realization that xylan constitutes a large proportion of biomass has generated interest in exploiting the compound for value-added precursors, but few chassis microorganisms can grow on xylose. Arabinose is part of lignocellulose biomass and can be metabolized with similar pathways to xylose, as well as an oxidative pathway. Like enzymes in many non-phosphorylative carbohydrate pathways, enzymes involved in L-arabinose pathways from bacteria and Archaea show metabolic and substrate promiscuity. A similar multiplicity of pathways was observed for other biomass-derived sugars such as L-rhamnose and L-fucose, but D-mannose appears to be distinct in that a non-phosphorylative version of the ED pathway has not been reported. Many bacteria and Archaea are able to grow on mannose but, as with other minor sugars, much of the information has been derived from whole cell studies with additional enzyme proteins being incorporated, and so far, only one synthetic pathway has been described. There appears to be a need for further discovery studies to clarify the general ability of many microorganisms to grow on the rarer sugars, as well as evaluation of the many gene copies displayed by marine bacteria.
\end{abstract}

Keywords: carbon metabolism; non-phosphorylative pathways; dehydratases; aldolases; alternative metabolism of sugars

\section{Introduction}

The Emden-Meyerhof-Parnas (EMP) pathway for glycolysis is regarded widely as the most important example of a degradative route to yield energy and provide co-products for the further 
construction of polymers in many microorganisms used in industrial production. However, it is either modified, complemented or replaced by alternative pathways in different bacteria and Archaea. In some microorganisms such as Zymomonas mobilis and Pseudomonas putida, the Entner-Doudoroff (ED) pathway plays a key role. The ED pathway and its variations do not provide a high ATP yield, and differ in key principles from the EMP pathway. The roles of these two major routes are discussed in detail in a recent review [1] where they describe how the ED pathway enzymes and complete ED and EMP pathway modules have been used to reformulate carbon metabolism in production strains and for the construction of cell-free enzymatic pathways. What is generally overlooked is the occurrence of other pathways for carbohydrate utilization, predominantly focused on sugars present in biomass rather than purified chemical species. Many of these alternative pathways are emerging as new thermophilic species are isolated and characterized, often from Archaea, for example, the recent discovery of an oxidative pathway for D-ribose catabolism in the archaeon Haloarcula [2]. The alternative pathways currently known are based largely on the Weimberg and Dahms pathways and have been illuminated by heterologous transfers of genes and multi-enzyme gene cassettes into production strains. This review examines some of the recent results from research on these pathways and individual enzymes that transform simple oligosaccharides into valuable precursors.

\section{Important Enzymes of the ED Pathway/Non-Phosphorylative Pathways}

\subsection{Dehydratases}

The initial reaction of ED pathways includes an oxidation of glucose or galactose by an aldohexose dehydrogenase for non- and semi-phosphorylative (np- and sp-ED) pathways or by glucose-6-phosphate dehydrogenase (ZWF) in the classical ED pathway. Following oxidation, the resulting sugar acid is dehydrated, marking a characteristic step in the operation of all ED pathways. In the classical ED pathway of most bacteria (e.g., Pseudomonas spp., Escherichia coli and Z. mobilis), this step is performed by 6-phosphogluconate dehydratase (EDD), while in the archaeal np-ED pathway, this step is catalyzed by a gluconate dehydratase (GAD). Despite the fact that both enzymes fulfil a similar function in the pathway, EDD and GAD differ in their protein structure and characteristics. EDDs share a conserved iron-sulphur cluster and belong to the dihydroxyacid dehydratase/EDD (IlvD/EDD) family. By contrast, most GADs from Archaea are activated by $\mathrm{Mg}^{2+}$ or $\mathrm{Mn}^{2+}$ and belong to the enolase superfamily. In the context of their ED pathways, EDD from E. coli, Z. mobilis, Pseudomonas aeruginosa and Helicobacter pylori are highly conserved and share $49 \%$ residues including a $4 \mathrm{Fe}-4 \mathrm{~S}$ cluster. The presence of the iron-sulphur cluster in EDD can hinder its use in eukaryotic production hosts (e.g., yeast), as the uptake is highly regulated and bioavailable iron is limited in eukaryotic cells [3].

Several of the EDDs have been studied in more detail and shown to be activated by $\mathrm{Fe}^{2+}, \mathrm{Mn}^{2+}$ and $\mathrm{Mg}^{2+}$, as well as other reducing agents such as glutathione, cysteine and thioglycolate [4,5]. An overview and comparison of dehydratases from other enzyme families are given in Table 1. 
Table 1. Overview of dehydratases from IlvD/EDD, enolase and xylose isomerase-like superfamilies. D-Glc: D-gluconate, D-Xyl: xylonate, L-Fuc: fuconate, D-Gal: galactonate, D-Man: D-mannonate, L-Man: L-mannonate, D-Rib: D-ribonate, Iso: DL-isovalerate, Dh-iso: 2,3-dihydroxyisovalerate, D-Ara: D-arabinonate, GlcA: glucuronate, GalA: galacturonate, L-Thr: L-threonate, L-Ara: L-arabinonate, L-Rha: L-rhamnonate, L-Lyx: L-lyxonate, L-Gul: L-gulonate, L-Ido: L-idonate.

\begin{tabular}{|c|c|c|c|c|c|c|}
\hline Enzyme & EC & Abbreviation & Pathway & Species ${ }^{1}$ & Active Substrates $^{2}$ & Activating Cofactors/Additives \\
\hline \multicolumn{7}{|l|}{ IlvD/EDD superfamily } \\
\hline $\begin{array}{l}\text { 6-phospho-gluconate } \\
\text { dehydratase }\end{array}$ & 4.2 .13 & EDD & classical ED & $\begin{array}{l}\text { E. coli }[5,6] \\
\text { Z. mobilis }[4] \\
\text { P. aeruginosa [7] } \\
\text { P. flourescens }[8] \\
\text { P. putida [7] }\end{array}$ & 6-phosphogluconate & $\begin{array}{c}\mathrm{Fe}^{2+}, \text { glycerol-3-phosphate, } \\
\mathrm{Fe}^{2+}, \mathrm{Mn}^{2+}, \text { glycerol, gluconate, ascorbate } \\
\mathrm{Fe}^{2+}, \mathrm{Mg}^{2+}, \mathrm{Mn}^{2+} \\
\mathrm{Fe}^{2+}, \mathrm{Mg}^{2+}, \mathrm{Mn}^{2+}, \text { glutathione, cysteine } \\
\mathrm{Fe}^{2+}, \mathrm{Mg}^{2+}, \mathrm{Mn}^{2+}\end{array}$ \\
\hline gluconate dehydratase & 4.2 .1 .39 & GAD & np-ED/sp-ED & A. xylosoxydans [9] & $\begin{array}{l}\text { D-Glc, D-Xyl, L-Fuc, D-Gal, } \\
\text { D-Man, L-Man, D-Rib, Iso }\end{array}$ & $\mathrm{Mg}^{2+}, \mathrm{Mn}^{2+}$ \\
\hline dihydroxyacid dehydratase & & DHAD & $\begin{array}{l}\text { valine/isoleucine } \\
\text { synthesis }\end{array}$ & S.solfataricus [10] & $\begin{array}{l}\text { Dh-iso, glc, D-Xyl, D-Ara, } \\
\text { GlcA, GalA, D-Fuc, L-Thr }\end{array}$ & $\mathrm{Mg}^{2+}, \mathrm{Mn}^{2+}, \mathrm{Ba}^{2+}, \mathrm{NaCl}$ \\
\hline xylonate deydratase & 4.2.1.82 & XAD & pentose oxidation & C. crescentus [11] & D-Xyl & $\mathrm{Fe}^{2+}, \mathrm{Mg}^{2+}$ \\
\hline arabinoate dehydratase & 4.2.1.25 & AraC & pentose oxidation & A. brasiliense [12] & L-Ara, D-Xyl & $\mathrm{Fe}^{2+}, \mathrm{Mg}^{2+}$ \\
\hline \multicolumn{7}{|l|}{ Enolase superfamily } \\
\hline $\begin{array}{c}\text { gluconate/galactonate } \\
\text { dehydratase }\end{array}$ & 4.2.1.140 & GAD & np-ED/sp-ED & $\begin{array}{l}\text { S. solfataricus }[13,14] \\
\text { P. torridus }[15]\end{array}$ & $\begin{array}{l}\text { D-Glc, D-Gal, } \\
\text { D-Glc, D-Gal }\end{array}$ & $\begin{array}{c}\mathrm{Mg}^{2+}, \mathrm{Mn}^{2+}, \mathrm{Ni}^{2+}, \mathrm{Co}^{2+} \\
\mathrm{Mg}^{2+}\end{array}$ \\
\hline gluconate dehydratase & 4.2.1.39 & GAD & np-ED/sp-ED & $\begin{array}{l}\text { T. tenax }[16] \\
\text { C. pasteurianum }{ }^{3}[17] \\
\text { H. volcanii }[18]\end{array}$ & $\begin{array}{l}\text { D-Glc } \\
\text { D-Glc } \\
\text { D-Glc }\end{array}$ & $\begin{array}{c}\mathrm{Co}^{2+}, \mathrm{Mg}^{2+}, \mathrm{Ni}^{2+}, \mathrm{Cd}^{2+}\left(\mathrm{Fe}^{2+} \text { inhibits }\right) \\
\mathrm{Fe}^{2+}, \mathrm{Mg}^{2+}, \mathrm{Mn}^{2+}, \mathrm{Co}^{2+}, \text { reducing agents } \\
\mathrm{Mg}^{2+}, \mathrm{Mn}^{2+}\end{array}$ \\
\hline xylonate dehydratase & 4.2.1.82 & XAD & pentose oxidation & H. volcanii [19] & D-Xyl, D-Glc & $\mathrm{Mg}^{2+}$ \\
\hline arabinoate dehydratase & 4.2.1.5 & AraD & pentose oxidation & S. solfataricus [20] & D-Ara & \\
\hline rhamnonate dehydratase & 4.2.1.90 & RhamD & pentose oxidation & $\begin{array}{c}\text { E. coli [21] } \\
\text { S. typhimurium [21] } \\
\text { A. vinelandii [22] } \\
\text { Sphingomonas [23] }\end{array}$ & $\begin{array}{l}\text { L-Rha, L-Lyx } \\
\text { L-Rha, L-Lyx } \\
\text { L-Rha, L-Lyx, L-Man } \\
\text { L-Rha, L-Lyx, L-Man } \\
\end{array}$ & $\begin{array}{l}\mathrm{Mg}^{2+} \\
\mathrm{Mg}^{2+}\end{array}$ \\
\hline mannonate dehydratases & 4.2.1.8 & ManD & diverse & $\begin{array}{c}\text { E. coli }[24,25] \\
\text { C. salexigens }[24] \\
\text { S. enterica }[24,25] \\
\text { N. aromaticivorans [26] } \\
\text { many more }[25] \\
\end{array}$ & $\begin{array}{l}\text { D-Man, L-Gul } \\
\text { D-Man, L-Gul } \\
\text { D-Man, L-Ido } \\
\text { D-Man }\end{array}$ & $\begin{array}{l}\mathrm{Mg}^{2+} \\
\mathrm{Mg}^{2+} \\
\mathrm{Mg}^{2+} \\
\mathrm{Mg}^{2+}\end{array}$ \\
\hline fuconate dehydratase & 4.2.1.68 & FucD & L-fucose pathway & X. campestris [27] & L-Fuc, D-Ara & $\mathrm{Mg}^{2+}$ \\
\hline \multicolumn{7}{|c|}{ Xylose isomerase-like superfamily } \\
\hline mannonate dehydratase & 4.2 .1 .8 & ManD (uxuA) & $\begin{array}{l}\text { hexuronate } \\
\text { metabolism }\end{array}$ & $\begin{array}{c}\text { S. suis [28] } \\
\text { T. acidophilum [29] }\end{array}$ & $\begin{array}{l}\text { D-Man } \\
\text { D-Man }\end{array}$ & $\begin{array}{c}\mathrm{Mg}^{2+} \\
\mathrm{Mg}^{2+}, \mathrm{Mn}^{2+}, \mathrm{Ni}^{2+}, \mathrm{Co}^{2+}, \mathrm{Ca}^{2+}, \\
\text { B-mercaptoethanol }\end{array}$ \\
\hline
\end{tabular}

${ }^{1}$ References in brackets. ${ }^{2}$ Only substrates displaying $>10 \%$ of the maximal enzyme activity are shown. ${ }^{3}$ Unclear if enzyme is part of the allocated enzyme family. 
In the np-ED pathway, which has been studied predominantly in Archaea, D-gluconate is converted to 2-keto-3-deoxygluconate (KDG) via GAD. The activity of this enzyme was observed in all cell extracts known to operate the np-ED pathway (Sulfolobus solfataricus, S. acidocaldarius, Thermosplasma acidophilum, Picrophilus torridus, Thermoproteus tenax, Achromobacter xylosoxidans) and more recently also in Haloferax volcanii [18]. A more detailed investigation of the properties of the GAD in Archaea has been conducted for S. solfataricus, P. torridus and T. tenax [13-16,30]. All GAD enzymes displayed high protein sequence similarity (44\%), similar catalytic mechanisms, and belonged to the subgroup of mandelate racemase/muconate lactonising enzymes (MR/MLE), which are part of the enolase superfamily and characteristically incorporate $\mathrm{Mg}^{2+}$ ions [15]. The GAD from S. solfataricus was found to be active with gluconate and galactonate, which is in line with the previous discovery of promiscuity for the other ED pathway enzymes from the same organism such as glucose dehydrogenase and 2-keto-3-deoxygluconate aldolase (KDGA) [31].

Besides the archaeal dehydratases, GADs from Clostridium pasteurianum and A. xylosoxidans have been investigated more thoroughly $[9,17]$. The dehydratase from $A$. xylosoxidans was characterized closely in regard to its biochemical characteristics and evolutionary relationship. Surprisingly, the enzyme shows high substrate promiscuity in particular with D-xylonate, and is phylogenetically more related to the bacterial IlvD/EDD enzymes instead of the GAD enzymes present in Archaea.

\subsubsection{Dehydratases of the Enolase Superfamily}

Sugar acid dehydratases have a wide range of different functions in other metabolic pathways in addition to the importance of EDD and GAD in ED pathways. Most studies focus on metabolic routes starting from glucose or galactose as a substrate and neglect alternative substrates that can be used by organisms. The investigation of substrate specificities of enzymes like dehydratases or dehydrogenases often provide indicators for so-far-undiscovered carbohydrate pathways [32]. In particular, the study of single enzymes in superfamilies has helped to elucidate enzymes with identical mechanisms but different physiological roles $[21,24,33]$. Many dehydratases involved in the np-ED pathway in Archaea are members of the enolase superfamily encompassing enzymes with the same bi-domain structure and a conserved mechanism. In addition to dehydratases involved in the catabolism of hexoses in the ED pathway, dehydratases from the pentose degradation pathways also belong to the enolase superfamily, e.g., xylonate dehydratase from $H$. volcanii [19] and D-arabinonate dehydratase from S. solfataricus [20]. All the enzymes of this superfamily share structural similarities including an $\alpha+\beta$ capping domain, which dictates substrate specificity and a TIM-barrel domain for acid/base catalysis. All members of the superfamily share the same partial reaction in which a base in the active site abstracts the alpha proton of a carboxylic acid. Subsequently, an enolate anionic intermediate is formed and stabilized by a metal ion [34,35]. However, as the basic/acidic catalysts are not conserved across all members, the superfamily can be divided into four subgroups according to the position and identity of the catalytic residues. The four subgroups, enolase, 3-methylaspartate ammonia lyases, muconate lactonising enzymes (MLE) and mandelate racemases (MR), are classified by the reactions catalyzed by their members and their conserved structural characteristics.

Most of the dehydratases are part of the MR/MLE subgroups that are characterized by the presence of a histidine base for the abstraction of the alpha proton. Among these subgroups, several dehydratases have been identified including D-glucarate/L-idarate dehydratase, D-altronate/ D-mannonate dehydratase, D-galactonate dehydratase, D-gluconate dehydratase and L-rhamnonate dehydratase $[9,13,21,26,36]$. Further investigation of the MR/MLE subgroups, particularly those annotated as mannonate dehydratases, revealed that substrate specificity differed greatly from that expected from gene annotation [24,25]. For example, 43 members of the mannonate dehydratase (ManD) subgroup were recombinantly expressed to determine their enzyme activities. All of the enzymes tested could be divided functionally into three groups based on their substrate specificity and catalytic efficiency: (a) Enzymes with high efficiency on D-mannonate; (b) enzymes with low efficiency on D-mannonate and/or D-gluconate; (c) enzymes with no activity on either substrate. High-activity 
ManDs were found in organisms that lack the $u x u A$ gene that encodes for an additional ManD that is known to be involved in the degradation of hexuronates [37]. The authors hypothesized that in those organisms, the role of the high-efficiency ManDs was to compensate for the missing UxuA enzyme in the hexuronate metabolism. By contrast, organisms with low-efficiency ManDs mostly contained an $u x u A$ gene, which raised the question about the physiological function of low-efficiency ManDs in the corresponding organisms. Although further studies found no physiological roles for the low-efficiency dehydratases, Wichelecki et al. suggested that these enzymes could mark possible starting points for the metabolism of other sugar acids [24,25].

In Chromohalobacter salexigens DSM3043 and E. coli CFT073, the low-efficiency ManD revealed activity towards L-gulonate, while in Salmonella enterica subsp. Enterica, the enzyme showed activity towards L-idonate. However, only in C. salexigens was the dehydratase assumed to be a part of a physiologically relevant metabolism, whereas the dehydratase in E. coli and S. enterica could not be assigned to a metabolic pathway [24].

The enolase superfamily is an example of structurally similar enzymes showing diversity in their physiological function [35]. On a mechanistic level, this diversification in function is due to the variation in loops and other binding domains but not the catalytic domain. This comparison is similar to the family of amidohydrolases in which diverse loop structures determine the substrate specificity of the enzymes but do not necessarily interact with the substrate themselves. For example, among a group of 64 amidohydrolases, only 18 enzymes showed an interaction of the substrate with one of the loops [38]. Consequently, sequence similarity in catalytic sites does not necessarily correlate with similarity in physiological function and needs to be confirmed by enzyme activity assays.

\subsubsection{Dehydratases in Hexuronate Metabolism}

Glucose has been one of the main substrates in the investigation of many pathways and their enzymes (e.g., the ED pathway). However, microorganisms thrive in very diverse environments that enable access to a wide range of substrates beyond glucose. For example, hexuronic acids like D-glucuronate and D-galacturonate can serve as carbon sources in the metabolism of different organisms including Dickeya dadantii (formerly known as Erwinia chrysanthemi), E. coli, Bacillus subtilis, B. stearothermophilus and Aspergillus niger [39-43]. D-Glucuronate is a component of plant cell walls present in the form of glucuronoxylan, which can be broken down by fungi and bacteria [42,44]. In the intestine, D-glucuronate and D-galacturonate are present in the mucus and can serve as a carbon source for gut bacteria such as E. coli $[45,46]$. There are four different known pathways for the degradation of D-glucuronate, with three of them involving a dehydratase. The most ubiquitous pathway present in E. coli, B. subtilis and D. dadantii features the genes $u x u A, u x u B, u x a C$ and exuT, $k d g A$ and $k d g K$ that code for enzymes and transporters in the catabolism of hexuronates (Figure 1 ). Glucuronate is transported into the cell via the hexuronate transporter (ExuT) and then converted into the central metabolites pyruvate and glyceraldehyde-3-phosphate (GAP) by the action of five different enzymes [47]. First, glucuronate is isomerized into fructuronate via an uronate isomerase $(\mathrm{UxaC})$. A mannonate oxidoreductase (UxuB) converts fructuronate to mannonate, which is then converted into KDG by the action of a mannonate dehydratase (UxuA). KDG is also present as the central intermediate of the sp-ED and np-ED pathways where it can be phosphorylated by KDG kinase (KDGK) and cleaved into pyruvate and GAP by KDGA. The dehydratase involved here has a similar function as the GAD in the archaeal np-ED pathway, as it is the crucial enzyme for the formation of the central intermediate KDG. However, dehydratases of the hexuronate cluster $u x u A$ are mostly part of the xylose isomerase-like superfamily and show only very limited protein sequence identity to dehydratases of the enolase or IlvD/EDD superfamilies. 


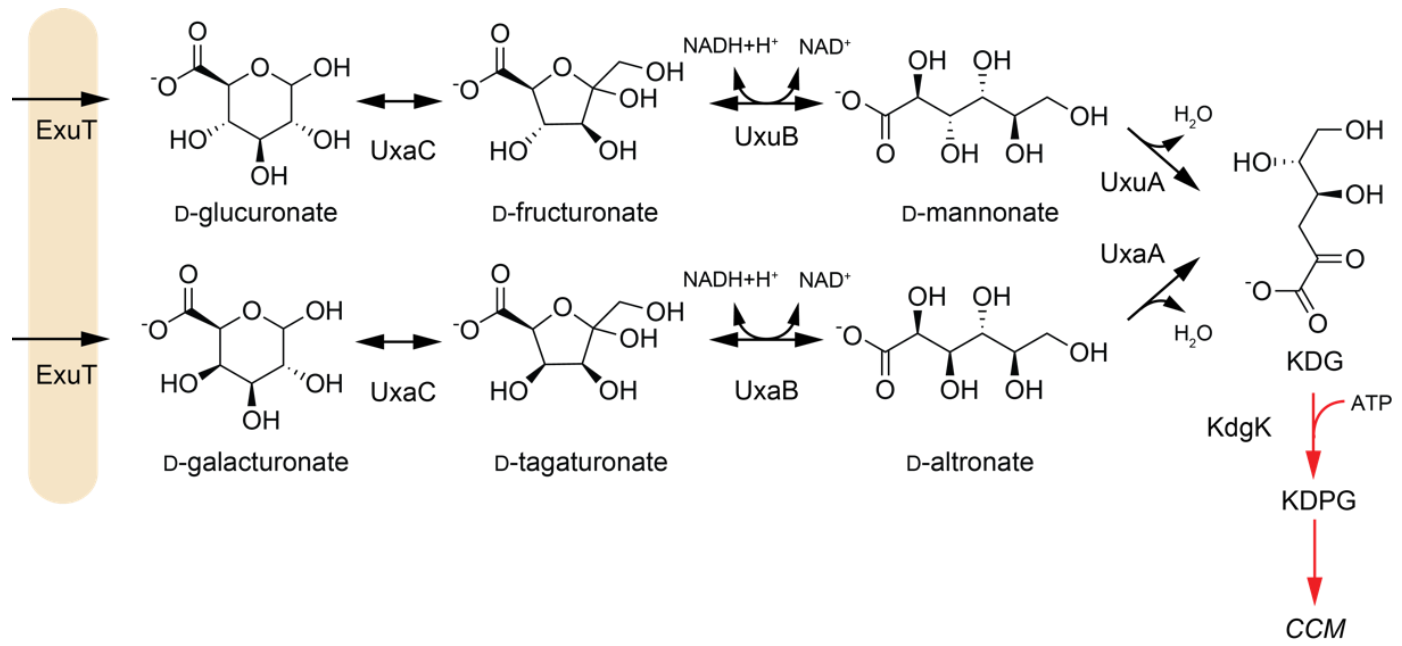

Figure 1. Metabolism of hexuronates in E. coli. Red arrows indicate analogous route to the Entner-Doudoroff (ED) pathway. ExuT: Hexuronate transporter, UxaC: Hexuronate isomerase, UxuB: Mannonate oxidoreductase, UxaB: Altronate oxidoreductase, UxuA: Mannonate dehydratase, UxaA: Altronate dehydratase, KdgK: 2-Keto-3-deoxygluconate kinase, KDG: 2-Keto-3-deoxygluconate, KDPG: 2-Keto-3-deoxy-6-phosphogluconate, CCM: Central carbon metabolism. Adapted from [47].

\subsubsection{Dehydratases of the IlvD/EDD Superfamily}

The IlvD/EDD superfamily comprises EDDs of the classical ED pathway, as well as dehydratases involved in the synthesis of the branched amino acids leucine, isoleucine and valine in eukaryotes. Despite the difference in their physiological roles, the two enzyme groups IlvD and EDD are structurally similar [48]. Members of the IlvD/EDD superfamily have been shown to contain Fe-S clusters in different coordination states. Stable [2Fe-2S] clusters have been found in a number of IlvD/EDD superfamily representatives in spinach [49], Rhizobium leguminosarum [50] and Caulobacter crescentus [11], while oxygen-labile [4Fe-4S] clusters have been identified in Z. mobilis and E. coli [51,52]. Other dehydratases from the IlvD/EDD superfamily were identified in the oxidative pentose pathways of Azospirillum brasilense, Burkholderia cepacia and C. crescentus [12,53]. The crystal structure of the D-xylonate dehydratase from C. crescentus was recently solved and revealed a tetrameric structure containing a [2Fe-2S] cluster including a $\mathrm{Mg}^{2+}$ ion at the monomer-monomer interface, similarly to the L-arabinonate dehydratase from R. leguminosarum studied previously $[11,50]$. The D-xylonate dehydratase from C. crescentus shares a $31 \%$ amino acid sequence identity with the EDD from E. coli, indicating an evolutionary relationship between the oxidative D-xylose pathway and the ED pathway [53]. Enzymes from the IlvD/EDD superfamily often display substrate promiscuity in a similar manner to the enzymes from the enolase superfamily. For example, the dihydroxyacid dehydratase (DHAD) from $S$. solfataricus showed the highest activity towards its natural substrate 2,3-dihydroxyisovalerate while maintaining more than $40 \%$ of its activity with D-gluconate, D-xylonate and D-arabonate and $10 \%$ of activity with D-glucuronate, D-galacturonate, D-fuconate and L-threonate [54]. The specific activity of the S. solfataricus DHAD heterologously expressed in E. coli was determined at $47 \mathrm{U} / \mathrm{mg}$ with 2,3-dihydroxyisovalerate as the substrate [54]. Carsten et al. expressed the same enzyme and measured a specific activity of $0.32 \mathrm{U} / \mathrm{mg}$ on 2,3-dihydroxyisovalerate using high-performance liquid chromatography [55]. Based on the results reported by Carsten et al., the DHAD appears to have a relatively low catalytic efficiency. However, in particular, DHAD remains an enzyme of industrial interest because of its promiscuous activity with different substrates, a property that might be used for the development of new biocatalytic processes and enzyme engineering [55-57]. 


\subsection{Aldolases}

Carbon-carbon bond formation is considered one of the most important and challenging steps in organic synthetic chemistry. Fundamental cellular processes such as the formation of carbohydrates, amino- and $\alpha$-hydroxy acids are dependent on aldolases. In chemical synthesis, the production of enantiopure compounds is of great importance but usually challenging to achieve with chemical catalysts. Instead, the use of chemo-, regio- and stereoselective enzymes provides more control over the formation of enantiopure compounds. Accordingly, aldolases have been used for the synthesis of carbohydrates, sugar analogues and enzyme inhibitors [58-60]. Besides their importance for applications in organic chemistry, aldolases play a crucial role in many naturally occurring carbohydrate pathways. For example, in both the EMP and ED pathways, a C6 sugar is converted into two $\mathrm{C} 3$ compounds by an aldolase. Aldolases can be divided into two different classes. Class I aldolases have a conserved lysine residue in the active site that enables the abstraction of a proton to form a Schiff base intermediate. This class of aldolase works independently of bivalent metal ions. By contrast, class II aldolases are known to be dependent on cofactors like $\mathrm{Zn}^{2+}, \mathrm{Fe}^{2+}$ or $\mathrm{Co}^{2+}$ ions for the deprotonation step.

Most KDG- and 2-keto-3-deoxy-6-phosphogluconate (KDPG) aldolases from the Archaeal domain have been shown either to be promiscuous towards different 2-keto-3-deoxy sugar acids or lack stereoselectivity $[15,61,62]$. Their substrate preference can be a key indicator for the existence of an organism's metabolic pathway as aldolases are found at crucial points in metabolic routes. For example, the KDG aldolase from S. solfataricus was shown to lack stereoselectivity as 2-keto-3-deoxygalactonate (KDGal) and KDG are cleaved into pyruvate and D-glyceraldehyde. This outcome was observed first in the reverse reaction, the addition of D-glyceraldehyde with pyruvate, which yielded KDG and KDGal in equal amounts [13]. As the first enzyme of the np-ED pathway in S. solfataricus, glucose dehydrogenase showed promiscuity towards galactose, and the promiscuity observed for KDG aldolase supported the fact that both sugars, glucose and galactose, can be metabolized in the np-ED pathway of S. solfataricus [13]. In contrast to $S$. solfataricus, the thermophilic anaerobe T. tenax is known to metabolize glucose through a modified EMP pathway involving sp-ED and np-ED pathways. In the sp-ED pathway, phosphorylation occurs at the level of the 2-keto-3-deoxy sugar acid, which is the reason that the KDG aldolase from T. tenax cleaves both KDPG and KDG [63]. The operation of the sp-ED pathway was believed initially to be exclusive to Haloarchaea, whereas the np-ED pathway was considered present in (hyper-)thermophilic Archaea. However, comparative genetic analysis of both thermophilic Archaea and Haloarchaea revealed that the ED pathway cluster is conserved in T. tenax, S. solfataricus, S. tokodaii and Halobacterium sp. NRC. ${ }^{14} \mathrm{C}$-tracer analysis on carbohydrate metabolism and biochemical analysis of recombinantly expressed KDG aldolases from T. tenax and S. solfataricus revealed that both enzymes show promiscuity towards phosphorylated and unphosphorylated compounds. Therefore, both organisms are able to operate by sp-ED and np-ED pathways [30].

The crystal structures of KDG aldolases from S. solfataricus [61], S. acidocaldarius [64] and T. tenax [65] were studied in further detail and found to show similar flexibility towards their aldehyde acceptors. All enzymes studied belong to the $\mathrm{N}$-acetylneuraminate lyase superfamily and depend on the formation of a Schiff base intermediate in the active site that usually contains a lysine residue. All three enzymes processed KDG, KDPG and KDGal, in line with the pathway promiscuity. However, there is no physiological reason for the aldolase promiscuity in T. tenax, as the organism is not able to grow on D-galactose [63]. Promiscuity of enzymes is often interpreted as a starting point for the divergence of function and the development of novel metabolic routes in the course of evolution [66]. It seems likely that the substrate flexibility in the aldolase of T. tenax is a relic of a former evolutionary step towards the development of other metabolisms, e.g., a np-ED pathway dependent on D-galactose. In summary, engineering of aldolases can be performed to increase their value in industrial applications, for example, the improvement in low-temperature activity for a hyperthermophilic aldolase for synthetic reactions at moderate temperatures [67]. In industry, many synthetic reactions rely on 
stereoselectivity of the biocatalyst, which is not a common feature for aldolases from most Archaea. However, promiscuous enzymes provide a good starting point for directed evolution or rational design. For example, the promiscuous KDPG aldolase from S. solfataricus was modified via site-directed mutagenesis to improve its diastereoselectivity [68]. In the reaction involving aldol addition, the wild-type enzyme produced almost equimolar amounts of KDG and KDGal. By way of an informed change of certain amino acid residues, a mutant library of 30 different variants could be created. Two mutants were identified that achieved high diastereoselectivity of either 93\% KDG or $88 \%$ KDGal despite having lower catalytic efficiencies.

Novel versions, as well as previously unknown carbohydrate pathways, are continuing to be discovered via the promiscuity of enzymes, especially aldolases. A recent paper by Tästensen et al. [69] has shown that $H$. volcanii can utilize D-galactose as an energy source, and a cluster of genes for the putative enzymes of the DeLey-Doudoroff pathway were identified such as D-galactose dehydrogenase, D-galactonate dehydratase, KDGal kinase and a 2-keto-3-deoxy-6-phosphogalactonate (KDPGal) aldolase, which was demonstrated to be promiscuous in utilizing both KDPGal and KDPG, the $\mathrm{C} 4$ epimer. A gene cluster for an $\mathrm{ABC}$ transporter was identified and a knock-out mutant showed its involvement in D-galactose uptake. These observations allowed the authors to claim the first report of D-galactose degradation by the DeLey pathway in Archaea.

\section{Alternative Metabolism of Sugars Other than Glucose}

The variety of carbohydrate pathways in organisms is dictated by their environmental conditions. Glucose has become the first choice as the carbon source in molecular studies and practice, as well as in industrial biotechnological processes. However, most microorganisms originate from an environment that displays a wider substrate spectrum than that found in laboratory-based cultivation. Lignocellulose, which consists of cellulose, hemicellulose and lignin, is the most abundant nonedible biomass on earth. The average lignocellulosic biomass contains about $20-40 \%$ hemicellulose, $30-50 \%$ cellulose and 15-25\% lignin [70]. In particular, hemicelluloses contain a variety of anhydrides of hexoses and pentoses such as xylan, arabinan, glucan, galactan, mannan and uronic acids. Corn stover is the most abundant lignocellulosic waste product in the U.S. and contains, on average, $37.4 \%$ cellulose, $21.1 \%$ xylan, $18 \%$ lignin, $2.9 \%$ arabinan, $2 \%$ galactan and $1.6 \%$ mannan [71]. Although this composition varies with the source of the biomass, the most abundant component is xylan, which makes up $15-30 \%$ in annual plants, $20-25 \%$ in hardwoods and $7-12 \%$ in softwoods. Readily available biomass (e.g., waste-streams) can be exploited to reduce the cost of substrate in order to optimize biotechnological fermentation processes to achieve economic viability.

Metabolic engineering in production strains such as E. coli, S. cerevisiae and Corynebacterium glutamicum is performed to exploit abundant biomass and achieve high yields, productivities and titres. However, the design capacity in rational metabolic engineering approaches is inspired by fundamental knowledge and discovery of carbohydrate pathways. Fungi, bacteria and archaea harbor a variety of metabolic pathways to catabolize the sugars present in lignocellulosic biomass, and they offer opportunities for the design of novel industrial biotechnological processes. The following section highlights oxidative pathways for sugars such as D-xylose, L-arabinose, L-rhamnose and L-fucose and the main enzymes involved in those pathways that could find uses in the field of metabolic engineering.

\subsection{D-Xylose Metabolism}

Hydrolysis of lignocellulosic biomass yields glucose and xylose as the most abundant monosaccharides available for bioconversion [72]. Many microorganisms naturally use xylose as a growth substrate, and several bacteria, yeast and fungi are capable of fermenting xylose to ethanol [73]. The major applied research efforts in this area have been focused on strain improvement by the incorporation of other xylose metabolic pathways, reducing the amount of xylitol production and solving redox imbalances by modulating gene expression of the nonoxidative pentose phosphate (PP) pathway [74]. Simultaneous fermentation of glucose and xylose has been investigated increasingly 
in recent years [75] in order to make use of the major portion of carbon in lignocellulosic feedstock. Four different xylose degradation pathways have been described in microorganisms so far. Most bacteria use the xylose isomerase (XI) pathway converting D-xylose into D-xylulose-5-phosphate (X5P), which enters the central carbon metabolism (CCM) via the PP pathway. In a first step, D-xylose is isomerized to D-xylulose by xylulose isomerase, followed by phosphorylation to X5P by xylulokinase. The oxo-reductive pathway is present in fungi and some yeasts and, similarly to the XI pathway, also yields X5P via phosphorylation of xylulose. However, in contrast to a single isomerization, D-xylopyranose is reduced to xylitol followed by an oxidation to xylulose, which is then phosphorylated. The Weimberg and Dahms pathways, which in contrast, do not rely on phosphorylation, metabolize several pentose sugars including L-arabinose and D-xylose to intermediates that are used in the CCM, e.g., the tricarboxylic acid (TCA) cycle (Figure 2). Instead of conversion to the PP pathway intermediate (X5P), D-xylose is oxidized to the central TCA intermediate $\alpha$-ketoglutarate in the Weimberg pathway and to pyruvate and glycolaldehyde in the Dahms pathway [76,77]. These two pathways share the initial oxidation of D-xylose to D-xylono-gamma-lactone and, after spontaneous or enzymatic hydrolysis of the lactone, D-xylonate is converted to 2-keto-3-deoxy-D-xylonate (KDX) by a xylonate dehydratase. The processing of the 2-keto-3-deoxy-sugar acid differs in the Weimberg and Dahms pathways. In the Dahms pathway, a KDX aldolase cleaves the C6 sugar into glycolaldehyde and pyruvate, while in the Weimberg pathway, a KDX dehydratase produces $\alpha$-ketoglutarate semialdehyde, which is then converted to the TCA intermediate $\alpha$-ketoglutarate.

Genes and enzymes of the oxidative pathways were first identified for the metabolism of L-arabinose in A. brasilense [12,78] and of D-xylose in C. crescentus [53], 40 years after the discovery of the Weimberg and Dahms pathways in Pseudomonas [76]. Stephens et al. [53] identified the xylose operon by screening a transposon mutagenesis library in which two differently annotated dehydrogenase genes, $x y l A$ and $x y l B$, were identified. Recombinant expression in E. coli verified that the dehydrogenase activity was attributed to the $x y l B$ gene, while $x y l A$ encoded a $\alpha$-ketoglutarate semialdehyde dehydrogenase, which generated $\alpha$-ketoglutarate, the final product of the pathway. The remainder of the genes in the operon coded for the enzymes xylonolactonase and xylonate dehydratase. The operon from C. crescentus is among the most used operons to convert production strains like C. glutamicum or Saccharomyces cerevisiae into microbes utilizing xylose [79-81]. In particular, the lactonase has been used in S. cerevisiae for the production of xylonate from xylose [82,83].

The Dahms pathway was established in a cell-based system using E. coli by Choi et al. [84] for the production of poly(lactate-co-glycolate), which has a number of biotherapeutic uses. E. coli was induced to utilize glucose and xylose simultaneously by inactivation of the glucose phosphotransferase system. The Dahms pathway was introduced from C. crescentus by plasmids carrying xylB (xylose dehydrogenase) and xylC (xylonolactonase). D-Lactonate glycolate was transformed by an evolved propionyl-CoA-transferase followed by polymerization with a polyhydroxyalkanoate (PHA) synthase. Yield was measured under the control of each of the five different promoters, and it was found that the concentrations of D-lactic acid and ethylene glycol increased.

Boer et al. [85] described the in vitro characterization of the oxidative D-xylose pathway (Dahms pathway). They determined the most suitable enzymes for the multi-enzyme cascade that leads from D-xylose or D-xylonolactone to glycolic acid, ethylene glycol and lactic acid from crude biomass. The D-xylonolactone hydrolysis reaction was found to be rate-limiting, but an enhanced IlvD/EDD family D-xylonate dehydratase from C. crescentus as an enolase family equivalent could not be discerned. The oxidation of glycoaldehyde to glycolic acid was improved by using E. coli aldehyde dehydrogenase or A. brasiliense $\alpha$-ketoglutarate semialdehyde dehydrogenase.

D-Xylose metabolism in archaea initially remained unknown until a xylose-specific dehydrogenase in Haloarcula marismortui suggested an oxidative metabolism for the pentose sugar similar to that found in other non-phosphorylative pathways in Archaea [32]. The essential genes for a phosphorylative pathway, via xylose isomerase and xylulose kinase, are missing in H. volcanii, supporting the observation that it is only operating an oxidative xylose pathway. The identification of the complete oxidative 
xylose pathway in Archaea was revealed in $\mathrm{H}$. volcanii by a combination of growth experiments on ${ }^{13} \mathrm{C}$-labelled xylose, DNA microarray analysis and enzyme activity assays [19]. The metabolism of the archaeon was found to resemble the Weimberg pathway, starting with oxidation by a D-xylose dehydrogenase, followed by conversion to $\alpha$-ketoglutarate by a xylonate dehydratase (XAD) and two dehydration steps (Figure 2). Other genes for the oxidative pathway were identified and their corresponding enzymes, xylose dehydrogenase $(\mathrm{XDH})$ and $\mathrm{XAD}$, were characterized. The XAD from $H$. volcanii belonged to the enolase superfamily, in contrast to the dehydratase from $C$. crescentus, which was found to be a member of the IlvD/EDD superfamily. Xylose pathways in both H. volcanii and S. solfataricus share promiscuity towards the pentose L-arabinose, which is further discussed in the following section and presented in Figure 2.

S. solfataricus

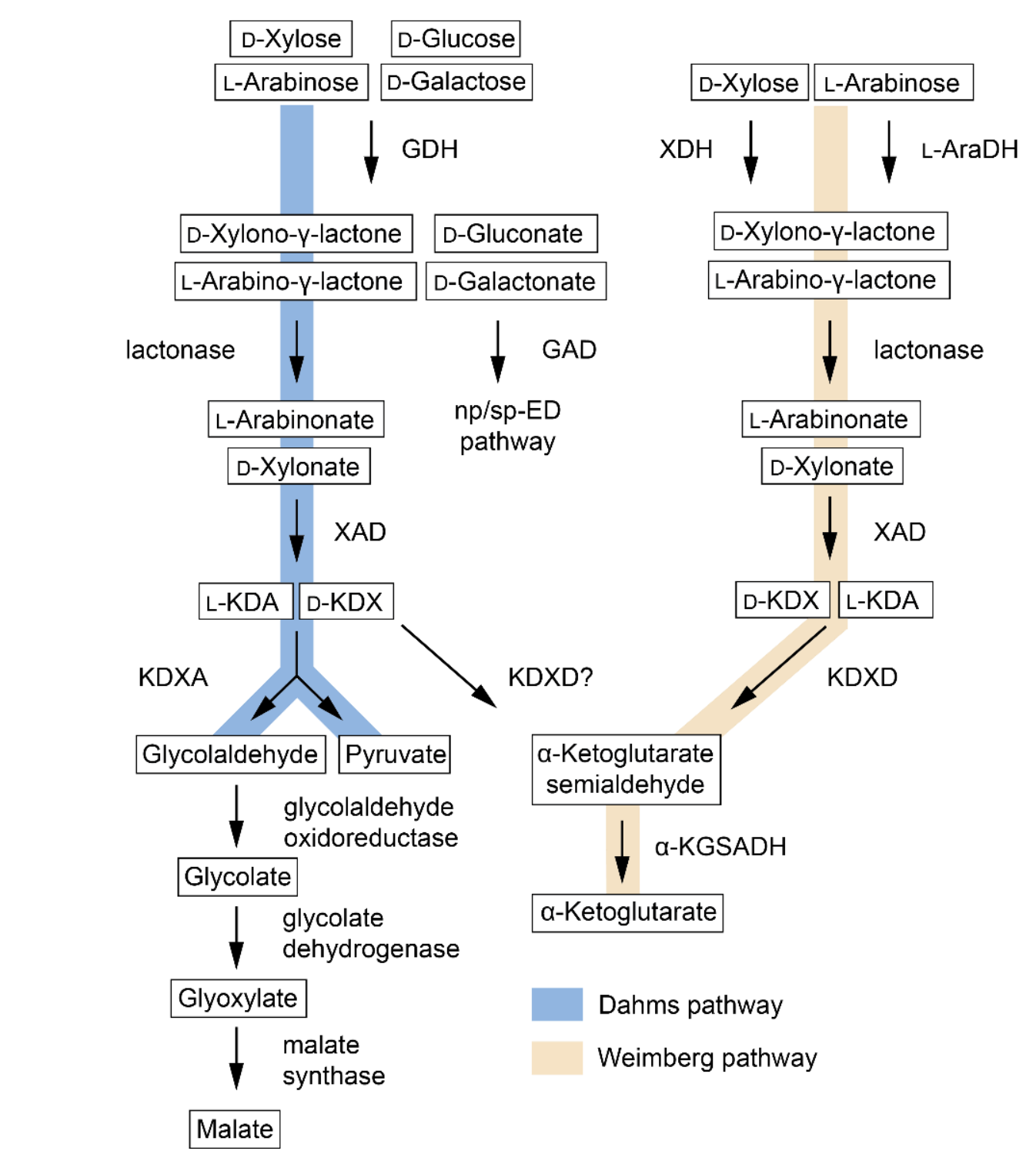

H. volcanii

Figure 2. Overview of the Weimberg (brown) and Dahms (blue) pathways and promiscuous pathways for D-xylose and L-arabinose in S. solfataricus and H. volcanii. GDH: Glucose dehydrogenase, XDH: D-xylose dehydrogenase, L-AraDH: L-arabinose dehydrogenase, GAD: Gluconate dehydratase, XAD: Xylonate dehydratase, D-KDX: 2-Keto-3-deoxy-D-xylonate, L-KDA: 2-Keto-3-deoxy-L-arabinonate, KDXA: KDX aldolase, KDXD: KDX dehydratase, $\alpha$-KGSADH: $\alpha$-Ketoglutarate semialdehyde dehydrogenase. 
Borgström et al. [86] described the channelling of xylose by S. cerevisiae through the pentose phosphate pathway and into glycolysis. They found that of the genes from the $C$. crescentus transformed into the yeast, the nonphosphorylated Weimberg pathway channels the xylose to alpha-ketoglutarate, allowing growth and providing a substrate for other metabolites. Substitution of the C. crescentus xylA with $k s a D$ from the C. glutamicum equivalent allowed growth on xylose after laboratory evolution of the gene. This observation is claimed to be the first demonstration of a functional Weimberg pathway in fungi. Halmsschlag et al. [87] compared the production from xylose of poly- $\gamma$-glutamic acid by the isomerase and Weimberg pathways by a genetically engineered strain of $B$. subtilis, and showed that the limiting diauxic growth in the strain could be overcome by the addition of glucose, resulting in high-yield production of the polymer from biomass substrates.

The realization that a large portion of biomass is composed of xylan has generated interest in exploiting the compound for the production of precursors and products of commercial value, as well as adding to the global bioeconomy with the possibility of replacing products currently produced from fossil feedstocks. A major problem is the few chassis organisms (such as Saccharomyces) currently in use that naturally have the enzyme pathways that allow growth on xylose. The oxidative xylose pathway was first expressed in Pseudomonas putida S12. Expression of a xylonate dehydratase was enough as the glucose dehydrogenase is promiscuous in P. putida S12 and also active with D-xylose [88]. A recent interesting paper examined the production of a number of industrially valuable compounds by the chassis strain of Pseudomonas putida KT2440, which is unable to metabolize xylose [89]. They compared yields of 14 possible metabolic compounds under conditions in which P. putida itself was inactive, but each engineered isolate could express one of three pathways for xylose utilization following acquisition of heterologous genes from E. coli and Pseudomonas taiwanensis. These were the isomerase, Weimberg and Dahms pathways, and expression of the latter required deletion of two endogenous genes including a regulator for glycoaldehyde degradation in the P. putida backbone, followed by adaptive evolution of all strains for increased growth rate. Essentially, their protocol allowed them to compare pseudo-isogenic strains, each expressing only one pathway. The highest yield of mono-rhamnolipids and pyocyanin were attained by the evolved Weimberg pathway strain or by an engineered strain using the isomerase pathway. They concluded that selection of the appropriate pathway with respect to its stoichiometry for one of the possible products was a feasible way of increasing yield and selecting a product for synthesis, and that the Weimberg and Dahms pathways were preferred for niche applications where xylose was the only carbon source.

\subsection{L-Arabinose Metabolism}

Arabinose is part of many types of lignocellulosic biomass together with xylose. The degradation of the natural isomer L-arabinose in most bacteria proceeds via an isomerase-dependent pathway [90]. However, L-arabinose can be metabolized via the Weimberg, Dahms or novel pathway variations in some bacteria and Archaea. The first genetic analysis of an oxidative L-arabinose pathway was performed in A. brasiliense, followed by studies in the archaeal species, S. solfataricus, S. acidocaldarius and $H$. volcanii $[12,20,91,92]$. The identification of a L-arabinose dehydrogenase indicated the existence of an oxidative pathway, which was confirmed by the identification of the missing enzymes L-arabinonate dehydratase, L-2-keto-3-deoxyarabinonate (L-KDA) dehydratase and L-arabinonolactonase, including the last enzyme $\alpha$-ketoglutaric acid semialdehyde dehydrogenase [78,93]. $\alpha$-Ketoglutarate is the final product of the pathway in A. brasiliense, entering the TCA cycle in a similar fashion to xylonate metabolism in $H$. volcanii, but unlike XAD from $H$. volcanii, the $\mathrm{N}$-terminal amino acid sequence of L-arabinonate dehydratase shows greater similarity to proteins belonging to the IlvD/EDD superfamily than those of the enolase superfamily. Accordingly, an evolutionary relationship between the L-arabinose pathway in A. brasiliense and the ED pathway and its variations has been suggested [12].

L-Arabinose metabolism in the archaeal kingdom has been studied in S. solfataricus, S. acidocaldarius and H. volcanii. The majority of archaeal pathways resemble the oxidative pathway found in A. brasiliense, with differences in their higher level of substrate promiscuity and a few modifications in Sulfolobus 
(Figure 2) [20,92]. Based on the activity of the glucose dehydrogenase with D-xylose and L-arabinose, Nunn et al. [91] suggested that D-glucose, D-galactose, L-arabinose and D-xylose were oxidized by the same dehydrogenase in Sulfolobus. However, dehydration of the pentose sugar acids is performed by a C5-specific dehydratase, which converts D-xylonate and L-arabinonate to KDX and L-KDA. The end products of the D-xylose/L-arabinose pathway are glycolaldehyde and pyruvate. Pyruvate enters the CCM via the TCA cycle, while two more enzymes convert glycolaldehyde into acetyl-CoA. Glycolaldehyde is converted further to malate via glycolaldehyde oxidoreductase and glycolate dehydrogenase [91]. L-Arabinose and D-xylose pathways are only partially promiscuous in $H$. volcanii, in contrast to the high levels of promiscuity observed for C5 and C6 sugars in S. solfataricus. Here, different dehydrogenases are present for the oxidation of the pentoses and hexoses [92].

Watanabe et al. [94] reported that the D-altronate dehydratase of Herbaspirillum huttiense functions as a D-arabinonate dehydratase in vitro, but on the contrary, the equivalent gene from Acidovorax avenae coded for an enzyme that functioned as a D-altronate dehydratase in a novel L-galactose pathway. They showed that the D-altronate dehydratase family of enzymes displayed both metabolic and substrate promiscuity, involving the non-phosphorylative pathways associated with D-arabinose, L-galactose and L-fucose pathways. Pentoses such as L-arabinose and D-arabinose may be converted to pyruvate and/or $\gamma$-ketoglutarate by way of the participation of a dehydrogenase and a hydrolase [95] and, at the same time, showed that the D-arabinose pathway was not evolutionarily related to the similar pathway found in Archaea. Lachaux et al. [96] reported the construction of a new synthetic pathway for the production of glycolic acid, a 2-carbon acid used in many industrial applications, that is currently manufactured from fossil sources. This pathway was dependent on the overexpression of three E. coli genes and could utilize L-arabinose besides D-glucose and D-xylose, and was considered best applied as a two-phase process with production separate from growth.

\subsection{L-Rhamnose Metabolism}

L-Rhamnose is found mostly as a structural polysaccharide in a variety of glycosides. In plants, it is a part of seed cell walls as a constituent of the polysaccharide rhamnogalacturonan [97]. The mechanism of L-rhamnose utilization has been studied in a number of organisms, which can grow on L-rhamnose as a sole carbon source including E. coli, T. acidophilum, Pichia stipitis, P. pastoris, A. niger and H. volcanii [97-101]. At least three main pathways for the degradation of L-rhamnose in microorganisms have been described. The phosphorylative pathway, which is present in most bacteria, was discovered together with the catabolism of L-fucose in E. coli [102]. The pathway cluster contains genes coding for an isomerase, a kinase and an aldolase. These enzymes convert L-rhamnose to L-lactaldehyde and dihydroacetone phosphate (DHAP), which readily enters glycolysis, whereas the fate of lactaldehyde is determined by the availability of oxygen. Under aerobic conditions, L-lactaldehyde is converted to L-lactate, which can be further processed to pyruvate. However, under anaerobic conditions, L-lactaldehyde is converted into the fermentation end product 1,2-propanediol, which is exported from the cell.

A non-phosphorylative L-rhamnose pathway, resembling the np-ED pathway for glucose in its numerous enzymatic steps, has been described in eukaryotic organisms (Figure 3). Initial evidence for such a pathway was found in the yeast-like fungus Pullularia pullulans, where the enzymes L-rhamnonate dehydratase and 2-keto-3-deoxy-L-rhamnonate (L-KDR) aldolase were shown to convert rhamnose into L-lactaldehyde and pyruvate [103]. A similar pattern was observed in the fungi P. stipitis and Debaryomyces polymorphus, [99]. Based on phylogenetic relationships of genes involved in ED and other alternative sugar pathways, Watanabe et al. identified the L-rhamnose pathway cluster in these fungi and found similar clusters in bacteria such as Azotobacter vinelandii [22]. The cluster consisted of four characteristic enzymes: L-rhamnose dehydrogenase, L-rhamnono-1,4-lactonase, L-rhamnonate dehydratase and 2-keto-3-deoxy-L-rhamnonate (L-KDR) aldolase. They also found that Cluster of Orthologous Groups (COGs) for enzymes of different sugar pathways varied, indicating that the pathways do not originate from a single ancestor. However, the total number for the COG is fairly 
small for all enzymes of known alternative sugar pathways, suggesting that different pathways evolved from a combination of a small number of ancestral enzymes. Each enzyme of the L-rhamnose pathway was characterized further and high levels of substrate promiscuity were observed. Among 16 different sugars tested, the L-rhamnose dehydrogenases from P. stipitis, Debaryomyces hansenii and Azotobacter vinelandii showed activity with L-rhamnose, L-lyxose, L-mannose and L-fucose, indicating that $\mathrm{C} 2, \mathrm{C} 3$ and $\mathrm{C} 4$ epimers can be oxidized by the dehydrogenases. By contrast, the L-rhamnono- $\gamma$-lactonase showed highly specific activity towards rhamnono- $\gamma$-lactone among 11 different sugar acids. The rhamnonate dehydratase was found to be similar to L-tartrate/galactarate dehydratase from Salmonella typhimurium and L-fuconate dehydratase from Xanthomonas campestris. Similarly to the dehydrogenase, the L-rhamnonate dehydratase showed high promiscuity and displayed high activity towards L-lyxonate and L-rhamnonate while retaining activity towards L-mannonate and L-fuconate [22].

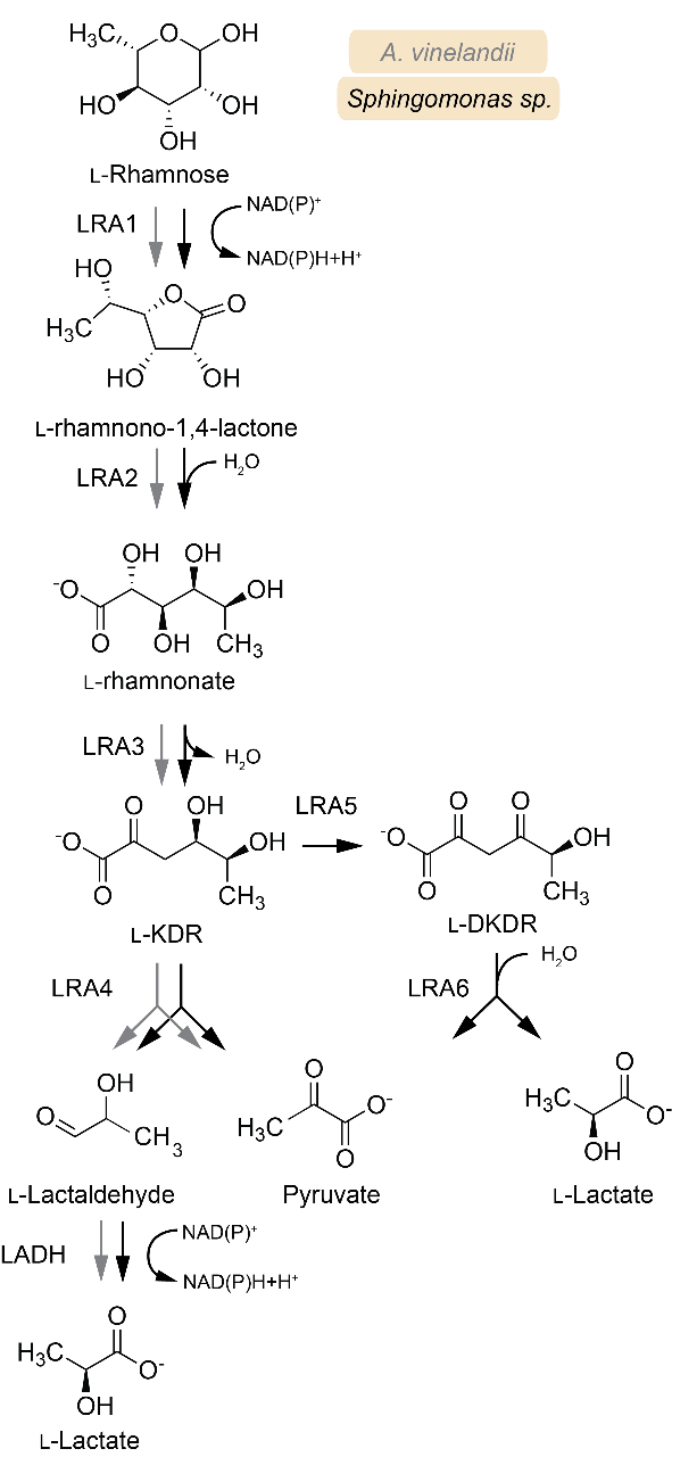

Figure 3. Overview of L-rhamnose metabolism in A. vinelandii (grey lines) and Sphingomonas sp. (black lines). LRA1: L-rhamnose-1-dehydrogenase, LRA2: L-rhamnono-lactonase, LRA3: L-rhamnonate dehydratase, LRA4: L-2-keto-3-deoxyrhamnonate aldolase, LRA5: L-2-keto-3-deoxyrhamnonate dehydrogenase, LRA6: L-2,4-diketo-3-deoxyrhamnonate hydrolase, LADH: L-lactaldehyde dehydrogenase, L-KDR: L-2-keto-3-deoxyrhamnonate, L-DKDR: L-2,4-diketo-3-deoxyrhamnonate. Adapted from [23]. 
Other studies investigating the L-rhamnose pathway in Sphingomonas revealed two more genes (LRA5 and LRA6) in addition to the cluster found in A. vinelandii. The enzymes coded by these genes resulted in a modification of the non-phosphorylative L-rhamnonate pathway described previously (Figure 3, grey arrows). In some species of Sphingomonas, the intermediate product L-KDR can be converted via a dehydrogenase and a hydrolase into pyruvate and L-lactate [23]. It was hypothesized that these enzymes evolved via gene duplication as the enzymes displayed strong similarity to dehydrogenases and dehydratases known already from L-arabinose and L-rhamnose pathways, and the pathway seemed to be promiscuous. A similar pattern has been discovered recently in Archaea. The gene cluster and the enzymes present in the oxidative pathway via L-2,4-diketo-3-deoxyrhamnonate have been detected in $H$. volcanii. A recent publication by Reinhardt et al. [104] reported the existence of the L-rhamnose catabolism gene cluster in the halophilic archaeon $H$. volcanii, and their essential nature was demonstrated with the aid of knockout mutants to provide a comprehensive description of L-rhamnose catabolism in Archaea. Others have provided evidence for the existence of L-rhamnose isomerase coded in the genome of the hyperthermophile Caldicellulosiruptor obsidiansis and noted its application for the synthesis of rhamnulose [105]. A fusion protein composed of RmlC (a 3,5-epimerase) and RmlD (a 4-reductase) was discovered in the microalga Prymnesium parvum and found to persist across the Haplophyta and Gymnodiniaceae families. These enzymes had been described in detail in plants and bacteria, but the biosynthetic enzymes had not been investigated in microalgae [106].

The gene clusters of L-rhamnose metabolism were compared in 32 fungal species. The cluster first described in P. stipitis is present only in an identical form in closely related species. Surprisingly, the aldolase (LRA4) is not found as part of the cluster in many species, but the transcription factor TRC1 was found to be a conserved part of the cluster in many species [107]. The study of promoter genes in the L-rhamnose cluster of $P$. pastoris allowed identification of strong rhamnose-inducible promoters for expression of target proteins [100]. Promoters for heterologous expression in P. pastoris commonly used are methanol-inducible, which are disadvantageous due to the hazardous and flammable nature of the methanol inducer. Induction with L-rhamnose overcomes these drawbacks and are the preferred option for production purposes.

\subsection{L-Fucose Metabolism}

L-Fucose is a common component of $\mathrm{N}$ - and O-linked glycans and glycolipids present in mammals. The hexose is highly abundant as part of the glycans covering epithelial cells in the intestine, making this sugar an interesting target for medical research [108]. L-Fucose is present also in cell walls of plants, fungi and bacteria as part of their exopolysaccharide structure. Different species of seaweed contain fucoidan, a sulphated polysaccharide structure consisting of L-fucose residues. [109]. Several species of gut bacteria attach to fucosylated glycans in the intestine [110] and release fucosidases that cleave L-fucose monomers, which can then be imported into the cell and used as a carbon source [111]. A L-fucose metabolism still exists in E. coli, although it does not express fucosidases. It is metabolised in a similar way to L-rhamnose and converted to L-lactataldehyde via a phosphorylative pathway that has been verified in E. coli and Bacteroides thetaiotaomicron [111,112]. Similarly to hexoses in the glycolysis, an isomerase, a kinase and an aldolase are fundamental parts of the pathway [98]. L-Lactaldehyde is processed further depending on the presence of oxygen as described earlier [112]. Liu et al. [113] in a recent paper described a simple one-pot synthesis of L-fucose by E. coli engineered to express 2 '-fucosyllactose, which was converted to L-fucose in industrially acceptable yields, unlike other methods involving enzymatic digestion of microbial exopolysaccharides enriched for L-fucose.

Comparative microarray studies allowed identification of a genomic island in Campylobacter jejuni, which exhibited a six- to nine-fold upregulation upon growth on L-fucose [114]. However, only a gene encoding for a fucose transporter $(f u c P)$ and an aldolase $(f u c A)$ showed homology to known genes in the phosphorylative pathway for L-fucose in E. coli. In particular, the absence of a gene coding for a L-fucolose kinase ( $f u c K)$ suggested the presence of a different pathway for L-fucose catabolism in C. jejuni. The existence of an alternative non-phosphorylative L-fucose pathway is 
supported by the discovery of a L-fuconate dehydratase in X. campestris [27]. The enzyme was found to have promiscuous activity towards L-galactonate, D-arabinonate, D-altronate, L-talonate and D-ribonate. Together with the identification of a L-fucose pathway cluster, a non-phosphorylative processing of L-fucose was proposed, proceeding by a similar pattern to the L-rhamnose pathway mentioned previously for Sphingomonas, but the 2-keto-3-deoxy sugar is proposed to be oxidized to 2,4-diketo-3-deoxy-L-fuconate, which can be cleaved into pyruvate and L-lactate.

A complete non-phosphorylative L-fucose pathway was solved for $S$. solfataricus using a systematic approach [62]. This study compared metabolic intermediates, transcripts and phenotypes of cells grown on L-fucose to cells grown on D-glucose. Genes were identified and enzymes tested for activity. They revealed that a locus of L-arabinose metabolism displayed up-regulated transcript levels in cells grown on L-fucose. Enzyme assays verified that L-fucose was metabolized via a promiscuous pathway, which also catabolized L-arabinose. A previously unknown non-phosphorylative L-fucose metabolic pathway was discovered by Watanabe [115] in the Gram-negative, strictly anaerobic bacterium Veillonella ratti, which was found to carry a gene cluster containing a putative dihydrodipicolinate synthase/N-acetylneuraminate lyase $(\mathrm{FucH})$. Watanabe proposes that the substrate specificity of the 2-keto-deoxysugar aldolases was acquired by convergent evolution and a similar aldolase was discovered in the same non-phosphorylative pathway in C. jejuni [115].

In summary, four different fucose degradation pathways have been described so far. The archaeal one, identified in S. solfataricus; the oxidative pathway in X. campestris; the phosphorylative pathway in other bacteria; and the non-phosphorylative one in $V$. ratti and C. jejuni.

\subsection{D-Mannose Metabolism}

Mannose occurs mostly in the form of a homo- or heteropolymer found in the hemicellulose component of plants such as ivory nut, fenugreek, guar gums and coffee beans, and is also highly abundant in the N-linked glycosylated proteins [116]. In most organisms, D-mannose is phosphorylated to mannose-6-phosphate by a hexokinase and can be further processed depending on cellular needs. If mannose is used as a growth substrate and directed towards the EMP pathway, mannose-6-phosphate is isomerized to fructose-6-phosphate by a phosphomannoisomerase. In eukaryotic cells, D-mannose can also be directed towards glycosylation via conversion by a phosphomannomutase to form $\alpha$-D-mannose-1-phosphate. Research on mannose catabolism in microorganisms is not as extensive as for more common sugars like those previously discussed, as it is used infrequently to culture strains in molecular or microbiological practice. Many bacteria and Archaea contain hydrolytic enzymes to break down carbohydrate polymers containing D-mannose. $\alpha$-Mannosidases from bacteria including Bacillus sp. [117], Thermotoga maritima [118,119] and few Archaea [120] were investigated for their processing of glycosylated proteins in eukaryotic cells [121]. By contrast, $\beta$-mannanases and endo-1,4- $\beta$-mannosidases have been studied in a range of microorganisms for their hydrolytic activity on polymers containing 1,4- $\beta$-mannan such as those found in hemicellulose [118,122-124]. However, no non-phosphorylative version similar to the np-ED, Weimberg or Dahms pathways has been identified so far for D-mannose. RNA sequencing of S. solfataricus cells grown on L-fucose and D-glucose revealed a downregulation of several genes that could be involved in a mannose metabolic pathway. For example, an $\alpha$-mannosidase, a putative endo- $1,4-\beta$-mannosidase, an additional sugar dehydrogenase and a glyceraldehyde oxidoreductase showed lower transcription and expression levels [62]. As S. solfataricus and other Archaea, which operate on the np-ED pathway, already contain KDGA, a promiscuous pathway with D-mannose as a substrate would be possible with the presence of only two enzymes. For a complete non-phosphorylative conversion starting from D-mannose, only aldohexose dehydrogenase that is active on D-mannose and a mannonate dehydratase are needed. In S. solfataricus, glucose dehydrogenase and gluconate dehydratase show activity with numerous substrates, but not with D-mannose and D-mannonate [14,31]. In addition, although highly promiscuous, DHAD has shown activity with a variety of different sugar acids but not with D-mannonate [10]. 
Nevertheless, dehydration of D-mannonate can be found in other sugar pathways, which may compensate for missing enzymes in an oxidative mannose pathway. One example is hexuronate metabolism, which has been studied in several bacteria and has been described earlier in Section 2.1.3. For the catabolism of hexuronates, a mannonate dehydratase (UxuA) converts D-mannonate to KDG, which is equivalent to the main intermediate of the np-ED pathway. In mutant strains of Rhodospseudomonas spheroides, the compounds D-mannonate, KDG and traces of gluconic acid accumulate during growth on D-mannose, suggesting that a non-phosphorylative oxidation occurs [125]. These results suggest the presence of a currently unknown alternative mannose metabolism. Nguyen et al. [126] reported a high-yield process for the production of D-mannose and ethanol from spent coffee grounds (SCG) using a simple but elongated process that involved pretreatment of the coffee waste with ethanol, enzymatic treatment with cellulase and pectinase of the galactomannans, yeast fermentation to produce ethanol, and removal of colour and pervaporation to isolate the ethanol and the D-mannose. While the yields were acceptable to industry, no costing of the process was provided. Saburi et al. [127] characterized D-mannose 2-epimerases from Runella slithyformis and Dyadobacter fermentans (in the acylglucosamine 2-epimerase superfamily) and demonstrated that the yields produced were higher than those of enzymes from Caldicellulsiruptor and Cellvibrio in the production of D-glucose from D-mannose. Although carbohydrate epimerases and isomerases are essential in the metabolism of carbohydrates, no information on the industrial significance of this enzyme class was provided.

Recently, Kopp et al. [29] identified and characterized the first archaeal mannonate dehydratase from Thermoplasma acidophilum (TaManD) and described the enzyme possible function in the catabolism of D-mannose. The recombinant TaManD displayed high specificity for D-mannonate and its lactone, D-mannono-1,4-lactone. A closer analysis of the genome of T. acidophilum indicated that the TaManD gene was adjacent to a mannose-specific aldohexose dehydrogenase (AldT). AldT has been shown to catalyse with high specificity the oxidation of D-mannose to D-mannonate [128,129]. Kopp et al. [29] used nuclear magnetic resonance (NMR) spectroscopy to prove that AldT mediated the oxidation of D-mannose and produced the substrates for TaManD conversion to KDG, indicating the possible presence of an oxidative metabolism of D-mannose in T. acidophilum. TaManD showed the closest homology to the xylose isomerase-like superfamily, and further analysis indicated that archaeal mannonate dehydratases are located next to putative aldohexose dehydrogenases rather than to a hexuronate gene cluster like in bacteria. Based on these findings, the authors postulated the possibility of a different physiological role of mannonate dehydratases in Archaea [29].

In a further study, Kopp et al. [130] assembled the shortest known synthetic pathway for the enzymatic conversion of mannose from SCG into lactic acid. The cell-free non-phosphorylative pathway produced $4.4 \mathrm{mM}$ lactic acid from $14.5 \mathrm{mM}$ SCG-derived mannose. The pathway comprised only four thermostable enzymes, three of which were from the T. acidophilum, including the newly identified TaManD and a 2-keto-3-deoxygluconate aldolase.

\section{Conclusions}

The extent and the use of the major glycolytic pathways have been reviewed by Kopp and Sunna, [1] who have analysed the important factors such as $\mathrm{NAD}(\mathrm{P}) \mathrm{H}$ supply and production, and in cell methods for the elimination of specific genes to increase cofactor levels and to change the ATP supply. These actions suggest decoupling ATP from product formation and substituting the EMP pathway with the ED one to give lower biomass and ATP formation but higher flux and yields. They endorse the cell-free approach where all cofactors that are normally produced intracellularly have to be provided externally or supplied by additional enzymes, allowing the assembly of novel metabolic pathways from recombinant cells or purified enzymes. The cell-free approach allows the rapid testing of variations in the pathway providing prototyping and testing. The construction of a non-phosphorylative ED pathway makes them preferable in comparison to the EMP pathway as it requires a minimal number of cofactors and a reduced number of enzymes. Moreover, the 
non-phosphorylative oxidative pathways are not limited to glucose but are appropriate for the other sugars found in biomass, as well as glucose in spite of the lower energy yield compared to the EMP pathway.

It is difficult to forecast future developments in this area. There has been a significant interest in the degradation of complex polysaccharides to more simple metabolites that have the attributes of the EMP and ED pathways. Examining individual pathways for the hydrolysis of specific carbohydrates has led to a wider examination of the genomic information available. It has been reinforced by the realization that marine bacteria have access to a wide range of complex sugars and sulphate-modified residues so that seaweeds provide the oceans with significant supplies of carbon. It is estimated that $173 \mathrm{Tg}$ of carbon is sequestered annually by macroalgae such as Macrocystis and Sargassum [131], but there is only limited evidence of how the glycans are broken down into simpler sugars. A single cell study of the complex carbohydrate degradation patterns in poribacterial symbionts from marine sponges showed that they degraded glycosaminoglycan chains of proteoglycans and other glycoproteins, and proposed that they were efficient scavengers and recyclers of specific groups of carbon compounds [132]. An enzymatic cascade in Formosa agariphila degrades ulvan, a consequence of the presence of the well-known species Ulva, which forms extensive 'blooms'. The cascade consisted of 12 biochemically-characterized enzymes that break down ulvan into fermentable polysaccharides and constitute a (potentially) renewable resource, as well as allowing the limitation of recreational ecological effects caused by the alga [133]. A recent report has shown that the isolate 'Lentimonas' sp. CC4 (Verromicrobia) that specializes in degrading fucoidan, a complex-resistant brown algal glycan, possesses over 100 fucosidases and sulphatases, most of which are encoded by a megaplasmid [134]. A commentary by Cuskin and Lowe [135] draws comparison with the situation reported for Bacteroides ovatus, which targets plant xylan for degradation [136], but only 18 enzymes are required (organized also into two groups), and similarly, 'Lentimonas' CC4 is able to degrade fucoidan from different algal groups by expressing discrete enzyme groups dependent on the source. There must be a considerable metabolic cost to express the hundreds of enzymes involved and the construction of a proteinaceous bacterial microcompartment for fucose metabolism resulting in segregation from toxic intermediates [134]. It appears that further research into the roles of the various enzymes and the energy relationships involved are a worthwhile target that may be more enlightening than elucidation of simple pathways in other bacteria for the production of fermentable sugars. There is the prospect of extensive 'pick and mix' experimentation to unravel the role(s) of the many enzymes. Cuskin and Lowe [135] suggest that the complexity of the fucoidan-degrading enzymes may allow 'Lentimonas' to avoid competition with faster growing species of bacteria that degrade the more accessible glycans, and there may be other complex and alternative gene solutions that need to be revealed from the marine bacterial field.

Author Contributions: All authors listed have made a substantial, direct and intellectual contribution to the work, and approved it for publication. All authors have read and agreed to the published version of the manuscript.

Funding: D.K. was supported by an international Macquarie University Research Excellence Scholarship (iMQRES).

Conflicts of Interest: The authors declare no conflict of interest.

\section{Abbreviations}

$\begin{array}{ll}\text { AldT } & \text { aldohexose dehydrogenase } \\ \text { CCM } & \text { central carbon metabolism } \\ \text { DHAD } & \text { dihydroxyacid dehydratase } \\ \text { DHAP } & \text { dihydroacetone phosphate } \\ \text { ED } & \text { Entner-Doudoroff } \\ \text { EDD } & \text { 6-phosphogluconate dehydratase } \\ \text { EMP } & \text { Embden-Meyerhof-Parnas } \\ \text { ExuT } & \text { hexuronate transporter } \\ \text { GAD } & \text { gluconate dehydratase }\end{array}$




$\begin{array}{ll}\text { GAP } & \text { glyceraldehyde-3-phosphate } \\ \text { IlvD/EDD } & \text { dihydroxyacid dehydratase/EDD } \\ \text { KDG } & \text { 2-keto-3-deoxygluconate } \\ \text { KDGA } & \text { 2-keto-3-deoxygluconate aldolase } \\ \text { KDGK } & \text { 2-keto-3-deoxygluconate kinase } \\ \text { KDPG } & \text { 2-keto-3-deoxy-6-phosphogluconate } \\ \text { KDGal } & \text { 2-keto-3-deoxygalactonate } \\ \text { KDPGal } & \text { 2-keto-3-deoxy-6-phosphogalactonate } \\ \text { KDX } & \text { 2-keto-3-deoxy-D-xylonate } \\ \text { L-KDA } & \text { L-2-keto-3-deoxyarabinonate } \\ \text { L-KDR } & \text { 2-keto-3-deoxy-L-rhamnonate } \\ \text { ManD/UxuA } & \text { mannonate dehydratase } \\ \text { MLE } & \text { muconate lactonising enzymes } \\ \text { MR } & \text { mandelate racemases } \\ \text { MR/MLE } & \text { mandelate racemase/muconate lactonising enzymes } \\ \text { np-ED } & \text { non-phosphorylative } \\ \text { sp-ED } & \text { semi-phosphorylative } \\ \text { SCG } & \text { spent coffee grounds } \\ \text { UxaC } & \text { uronate isomerase } \\ \text { XAD } & \text { xylonate dehydratase } \\ \text { XDH } & \text { xylose dehydrogenase } \\ \text { XI } & \text { xylose isomerase } \\ \text { X5P } & \text { D-xylulose-5-phosphate } \\ \text { ZWF } & \text { glucose-6-phosphate dehydrogenase } \\ & \end{array}$

\section{References}

1. Kopp, D.; Sunna, A. Alternative carbohydrate pathways-Enzymes, functions and engineering. Crit. Rev. Biotechnol. 2020. [CrossRef] [PubMed]

2. Johnsen, U.; Sutter, J.-M.; Reinhardt, A.; Picki, A.; Wang, R.; Xiang, H.; Schönheit, P. D-Ribose catabolism in Archaea: Discovery of a novel oxidative pathway in Haloarcula species. J. Bacteriol. 2020, e00608-19. [CrossRef] [PubMed]

3. Benisch, F.; Boles, E. The bacterial Entner-Doudoroff pathway does not replace glycolysis in Saccharomyces cerevisiae due to the lack of activity of iron-sulfur cluster enzyme 6-phosphogluconate dehydratase. J. Biotechnol. 2014, 171, 45-55. [CrossRef] [PubMed]

4. Scopes, R.K.; Griffiths-Smith, K. Use of differential dye-ligand chromatography with affinity elution for enzyme purification: 6-phosphogluconate dehydratase from Zymomonas mobilis. Anal. Biochem. 1984, 136, 530-534. [CrossRef]

5. Gardner, P.R.; Fridovich, I. Superoxide sensitivity of the Escherichia coli 6-phosphogluconate dehydratase. J. Biol. Chem. 1991, 266, 1478-1483.

6. Kornberg, H.L.; Soutar, A.K. Utilization of gluconate by Escherichia coli. Induction of gluconate kinase and 6-phosphogluconate dehydratase activities. Biochem. J. 1973, 134, 489-498. [CrossRef]

7. Cuskey, S.M.; Wolff, J.A.; Phibbs, P.V., Jr.; Olsen, R.H. Cloning of genes specifying carbohydrate catabolism in Pseudomonas aeruginosa and Pseudomonas putida. J. Bacteriol. 1985, 162, 865-871. [CrossRef]

8. Kovachevich, R.; Wood, W.A. Carbohydrate metabolism by Pseudomonas fluorescens. III. Purification and properties of a 6-phosphogluconate dehydrase. J. Biol. Chem. 1955, 213, 745-756.

9. Kim, S.; Lee, S.B. Identification and characterization of the bacterial D-gluconate dehydratase in Achromobacter xylosoxidans. Biotechnol. Bioprocess Eng. 2008, 13, 436-444. [CrossRef]

10. Kim, S.; Lee, S.B. Catalytic promiscuity in dihydroxy-acid dehydratase from the thermoacidophilic archaeon Sulfolobus solfataricus. J. Biochem. 2006, 139, 591-596. [CrossRef]

11. Rahman, M.M.; Andberg, M.; Koivula, A.; Rouvinen, J.; Hakulinen, N. The crystal structure of D-xylonate dehydratase reveals functional features of enzymes from the Ilv/ED dehydratase family. Sci. Rep. 2018, 8, 865. [CrossRef] [PubMed] 
12. Watanabe, S.; Shimada, N.; Tajima, K.; Kodaki, T.; Makino, K. Identification and characterization of L-arabonate dehydratase, L-2-keto-3-deoxyarabonate dehydratase, and L-arabinolactonase involved in an alternative pathway of L-arabinose metabolism: Novel evolutionary insight into sugar metabolism. J. Biol. Chem. 2006, 281, 33521-33536. [CrossRef] [PubMed]

13. Lamble, H.J.; Milburn, C.C.; Taylor, G.L.; Hough, D.W.; Danson, M.J. Gluconate dehydratase from the promiscuous Entner-Doudoroff pathway in Sulfolobus solfataricus. FEBS Lett. 2004, 576, 133-136. [CrossRef]

14. Kim, S.; Lee, S.B. Identification and characterization of Sulfolobus solfataricus D-gluconate dehydratase: A key enzyme in the non-phosphorylated Entner-Doudoroff pathway. Biochem. J. 2005, 387, 271-280. [CrossRef]

15. Reher, M.; Fuhrer, T.; Bott, M.; Schönheit, P. The nonphosphorylative Entner-Doudoroff pathway in the thermoacidophilic euryarchaeon Picrophilus torridus involves a novel 2-keto-3-deoxygluconate- specific aldolase. J. Bacteriol. 2010, 192, 964-974. [CrossRef]

16. Matsubara, K.; Köhling, R.; Schönenberger, B.; Kouril, T.; Esser, D.; Bräsen, C.; Siebers, B.; Wohlgemuth, R. One-step synthesis of 2-keto-3-deoxy-D-gluconate by biocatalytic dehydration of D-gluconate. J. Biotechnol. 2014, 191, 69-77. [CrossRef] [PubMed]

17. Bender, R.; Gottschalk, G. Purification and properties of D-gluconate dehydratase from Clostridium pasteurianum. Eur. J. Biochem. 1973, 40, 309-321. [CrossRef]

18. Sutter, J.M.; Tästensen, J.B.; Johnsen, U.; Soppa, J.; Schönheit, P. Key enzymes of the semiphosphorylative Entner-Doudoroff Pathway in the haloarchaeon Haloferax volcanii: Characterization of glucose dehydrogenase, gluconate dehydratase, and 2-keto-3-deoxy-6-phosphogluconate aldolase. J. Bacteriol. 2016, 198, 2251-2262. [CrossRef]

19. Johnsen, U.; Dambeck, M.; Zaiss, H.; Fuhrer, T.; Soppa, J.; Sauer, U.; Schönheit, P. D-Xylose degradation pathway in the halophilic archaeon Haloferax volcanii. J. Biol. Chem. 2009, 284, 27290-27303. [CrossRef]

20. Brouns, S.J.J.; Walther, J.; Snijders, A.P.L.; Van De Werken, H.J.G.; Willemen, H.L.D.M.; Worm, P.; de Vos, M.G.J.; Anderson, A.; Lundgren, M.; Mazon, H.F.M.; et al. Identification of the missing links in prokaryotic pentose oxidation pathways: Evidence for enzyme recruitment. J. Biol. Chem. 2006, 281, 27378-27388. [CrossRef]

21. Rakus, J.F.; Fedorov, A.A.; Fedorov, E.V.; Glasner, M.E.; Hubbard, B.K.; Delli, J.D.; Babbitt, P.C.; Almo, S.C.; Gerlt, J.A. Evolution of enzymatic activities in the enolase superfamily: L-rhamnonate dehydratase. Biochemistry 2008, 47, 9944-9954. [CrossRef] [PubMed]

22. Watanabe, S.; Saimura, M.; Makino, K. Eukaryotic and bacterial gene clusters related to an alternative pathway of nonphosphorylated L-rhamnose metabolism. J. Biol. Chem. 2008, 283, 20372-20382. [CrossRef] [PubMed]

23. Watanabe, S.; Makino, K. Novel modified version of nonphosphorylated sugar metabolism-An alternative L-rhamnose pathway of Sphingomonas sp. FEBS J. 2009, 276, 1554-1567. [CrossRef] [PubMed]

24. Wichelecki, D.J.; Alyxa, J.; Vendiola, F.; Jones, A.M.; Al-obaidi, N.; Almo, S.C.; Gerlt, J.A. Investigating the physiological roles of low-efficiency D-mannonate and D-gluconate dehydratases in the enolase superfamily: Pathways for the catabolism of L-gulonate and L-idonate. Biochemistry 2014, 53, 5692-5699. [CrossRef]

25. Wichelecki, D.J.; Balthazor, B.M.; Chau, A.C.; Vetting, M.W.; Fedorov, A.A.; Fedorov, E.V.; Lukk, T.; Patskovsky, Y.V.; Stead, M.B.; Hillerich, B.S.; et al. Discovery of function in the enolase superfamily: D-mannonate and D-gluconate dehydratases in the D-mannonate dehydratase subgroup. Biochemistry 2014, 53, 2722-2731. [CrossRef]

26. Rakus, J.F.; Fedorov, A.A.; Fedorov, E.V.; Glasner, M.E.; Vick, J.E.; Babbitt, P.C.; Almo, S.C.; Gerlt, J.A. Evolution of enzymatic activities in the enolase superfamily: D-mannonate dehydratase from Novosphingobium aromaticivorans. Biochemistry 2007, 46, 12896-12908. [CrossRef]

27. Yew, W.S.; Fedorov, A.A.; Fedorov, E.V.; Rakus, J.F.; Pierce, R.W.; Almo, S.C.; Gerlt, J.A. Evolution of enzymatic activities in the enolase superfamily: L-fuconate dehydratase from Xanthomonas campestris. Biochemistry 2006, 45, 14582-14597. [CrossRef]

28. Zhang, Q.; Gao, F.; Peng, H.; Cheng, H.; Liu, Y.; Tang, J.; Thompson, J.; Wei, G.; Zhang, J.; Du, Y.; et al. Crystal structures of Streptococcus suis mannonate dehydratase (ManD) and its complex with substrate: Genetic and biochemical evidence for a catalytic mechanism. J. Bacteriol. 2009, 191, 5832-5837. [CrossRef]

29. Kopp, D.; Willows, R.; Sunna, A. Characterisation of the first archaeal mannonate dehydratase from Thermoplasma acidophilum and its potential in the catabolism of D-mannose. Catalysts 2019, 9, 234. [CrossRef] 
30. Ahmed, H.; Ettema, T.J.G.; Tjaden, B.; Geerling, A.C.M.; van der Oost, J.; Siebers, B. The semi-phosphorylative Entner-Doudoroff pathway in hyperthermophilic archaea: A re-evaluation. Biochem. J. 2005, 390, 529-540. [CrossRef]

31. Lamble, H.J.; Heyer, N.I.; Bull, S.D.; Hough, D.W.; Danson, M.J. Metabolic pathway promiscuity in the archaeon Sulfolobus solfataricus revealed by studies on glucose dehydrogenase and 2-keto-3-deoxygluconate aldolase. J. Biol. Chem. 2003, 278, 34066-34072. [CrossRef] [PubMed]

32. Johnsen, U.; Schönheit, P. Novel xylose dehydrogenase in the halophilic archaeon Haloarcula marismortui. J. Bacteriol. 2004, 186, 6198-6207. [CrossRef] [PubMed]

33. Yew, W.S.; Fedorov, A.A.; Fedorov, E.V.; Almo, S.C.; Gerlt, J.A. Evolution of enzymatic activities in the enolase superfamily: L-talarate/galactarate dehydratase from Salmonella typhimurium LT2. Biochemistry 2007, 46, 9564-9577. [CrossRef] [PubMed]

34. Babbitt, P.C.; Gerlt, J.A. Understanding enzyme superfamilies-Chemistry as the fundamental determinant in the evolution of new catalytic activities. J. Biol. Chem. 1997, 272, 30591-30594. [CrossRef] [PubMed]

35. Gerlt, J.A.; Babbitt, P.C.; Rayment, I. Divergent evolution in the enolase superfamily: The interplay of mechanism and specificity. Arch. Biochem. Biophys. 2005, 433, 59-70. [CrossRef]

36. Gulick, A.M.; Hubbard, B.K.; Gerlt, J.A.; Rayment, I. Evolution of enzymatic activities in the enolase superfamily: Identification of the general acid catalyst in the active site of D-glucarate dehydratase from Escherichia coli. Biochemistry 2001, 40, 10054-10062. [CrossRef]

37. Rothe, M.; Alpert, C.; Loh, G.; Blaut, M. Novel insights into E. coli's hexuronate metabolism: KduI facilitates the conversion of galacturonate and glucuronate under osmotic stress conditions. PLoS ONE 2013, 8, e56906. [CrossRef]

38. Seibert, C.M.; Raushel, F.M. Structural and catalytic diversity within the amidohydrolase superfamily. Biochemistry 2005, 44, 6383-6391. [CrossRef]

39. Portalier, R.; Robert-Baudouy, J.; Stoeber, F. Regulation of Escherichia coli K-12 hexuronate system genes: Exu regulon. J. Bacteriol. 1980, 143, 1095-1107. [CrossRef]

40. Hugouvieux-Cotte-Pattat, N.; Robert-Baudouy, J. Hexuronate catabolism in Erwinia Chrysanthemi. J. Bacteriol. 1987, 169, 1223-1231. [CrossRef]

41. Mekjian, K.R.; Bryan, E.M.; Beall, B.W.; Moran, C.P. Regulation of hexuronate utilization in Bacillus subtilis. J. Bacteriol. 1999, 181, 426-433. [CrossRef] [PubMed]

42. Shulami, S.; Gat, O.; Sonenshein, A.L.; Shoham, Y. The glucuronic acid utilization gene cluster from Bacillus stearothermophilus T-6. J. Bacteriol. 1999, 181, 3695-3704. [CrossRef] [PubMed]

43. Kuivanen, J.; Sugai-Guérios, M.H.; Arvas, M.; Richard, P. A novel pathway for fungal D-glucuronate catabolism contains an L-idonate forming 2-keto-L-gulonate reductase. Sci. Rep. 2016, 6, 1-9. [CrossRef] [PubMed]

44. Reis, D.; Vian, B.; Roland, J.C. Cellulose-glucuronoxylans and plant cell wall structure. Micron 1994, 25, 171-187. [CrossRef]

45. Chang, D.-E.; Smalley, D.J.; Tucker, D.L.; Leatham, M.P.; Norris, W.E.; Stevenson, S.J.; Anderson, A.B.; Grissom, J.E.; Laux, D.C.; Cohen, P.D.; et al. Carbon nutrition of Escherichia coli in the mouse intestine. Proc. Natl. Acad. Sci. USA 2004, 101, 7427-7432. [CrossRef] [PubMed]

46. Fabich, A.J.; Jones, S.A.; Chowdhury, F.Z.; Cernosek, A.; Anderson, A.; Smalley, D.; McHargue, J.W.; Hightower, G.A.; Smith, J.T.; Autieri, S.M.; et al. Comparison of carbon nutrition for pathogenic and commensal Escherichia coli strains in the mouse intestine. Infect. Immun. 2008, 76, 1143-1152. [CrossRef]

47. Peekhaus, N.; Conway, T. What's for dinner?: Entner-Doudoroff metabolism in Escherichia coli. J. Bacteriol. 1998, 180, 3495-3502. [CrossRef]

48. Egan, S.E.; Fliege, R.; Tong, S.; Shibata, A.; Wolf, R.E., Jr.; Conway, T. Molecular characterization of the Entner-Doudoroff pathway in Escherichia coli: Sequence analysis and localization of promoters for the edd-eda operon. J. Bacteriol. 1992, 174, 4638-4646. [CrossRef]

49. Flint, D.H.; Emptage, M.H. Dihydroxy acid dehydratase from spinach contains a [2Fe-2S] cluster. J. Biol. Chem. 1988, 263, 3558-3564.

50. Rahman, M.M.; Andberg, M.; Thangaraj, S.K.; Parkkinen, T.; Penttilä, M.; Jänis, J.; Koivula, A.; Rouvinen, J.; Hakulinen, N. The crystal structure of a bacterial L-arabinonate dehydratase contains a [2Fe-2S] cluster. ACS Chem. Biol. 2017, 12, 1919-1927. [CrossRef] 
51. Flint, D.H.; Emptage, M.H.; Finnegan, M.G.; Fu, W.; Johnson, M.K. The role and properties of the iron-sulfur cluster in Escherichia coli dihydroxy-acid dehydratase. J. Biol. Chem. 1993, 268, 14732-14742. [PubMed]

52. Rodriguez, M.; Wedd, A.G.; Scopes, R.K. 6-phosphogluconate dehydratase from Zymomonas mobilis: An iron-sulfur-manganese enzyme. Biochem. Mol. Biol. Int. 1996, 38, 783-789. [PubMed]

53. Stephens, C.; Christen, B.; Fuchs, T.; Sundaram, V.; Watanabe, K.; Jenal, U. Genetic analysis of a novel pathway for D-xylose metabolism in Caulobacter crescentus. J. Bacteriol. 2007, 189, 2181-2185. [CrossRef] [PubMed]

54. Carsten, J.M.; Schmidt, A.; Sieber, V. Characterization of recombinantly expressed dihydroxy-acid dehydratase from Sulfobus solfataricus-A key enzyme for the conversion of carbohydrates into chemicals. J. Biotechnol. 2015, 211, 31-41. [CrossRef]

55. Guterl, J.K.; Garbe, D.; Carsten, J.; Steffler, F.; Sommer, B.; Reiße, S.; Philipp, A.; Haack, M.; Rühmann, B.; Koltermann, A.; et al. Cell-free metabolic engineering: Production of chemicals by minimized reaction cascades. Chemsuschem 2012, 5, 2165-2172. [CrossRef] [PubMed]

56. Gao, C.; Li, Z.; Zhang, L.; Wang, C.; Li, K.; Ma, C.; Xu, P. An artificial enzymatic reaction cascade for a cell-free bio-system based on glycerol. Green Chem. 2015, 17, 804-807. [CrossRef]

57. Xie, L.; Wei, X.; Zhou, X.; Meng, D.; Zhou, R.; Zhang, Y.-H.P.J.; Xu, S.; You, C. Conversion of D-glucose to L-lactate via pyruvate by an optimized cell-free enzymatic biosystem containing minimized reactions. Synth. Syst. Biotechnol. 2018, 3, 204-210. [CrossRef]

58. Wong, C.; Whitesides, M. Chemical and enzymatic syntheses of 6-deoxyhexoses. Conversion to 2,5-dimethyl-4-hydroxy-2,3-dihydrofuran-3-one (Furaneol) and analogues. J. Org. Chem. 1983, 48, 3493-3497. [CrossRef]

59. Hecquet, L.; Hélaine, V.; Charmantray, F.; Lemaire, M. Enzymes catalyzing C-C bond formation for the synthesis of monosaccharide analogs. In Modern Biocatalysis: Stereoselective and Environmentally Friendly Reactions; Fessner, W.-D., Anthonsen, T., Eds.; Wiley-VCH: Weinheim, Germany, 2008; pp. 287-298.

60. Clapés, P.; Fessner, W.D.; Sprenger, G.A.; Samland, A.K. Recent progress in stereoselective synthesis with aldolases. Curr. Opin. Chem. Biol. 2010, 14, 154-167. [CrossRef]

61. Theodossis, A.; Walden, H.; Westwick, E.J.; Connaris, H.; Lamble, H.J.; Hough, D.W.; Danson, M.J.; Taylor, G.L. The structural basis for substrate promiscuity in 2-keto-3-deoxygluconate aldolase from the Entner-Doudoroff pathway in Sulfolobus Solfataricus. J. Biol. Chem. 2004, 279, 43886-44892. [CrossRef]

62. Wolf, J.; Stark, H.; Fafenrot, K.; Albersmeier, A.; Pham, T.K.; Müller, K.B.; Meyer, B.H.; Hoffmann, L.; Shen, L.; Albaum, S.P.; et al. A systems biology approach reveals major metabolic changes in the thermoacidophilic archaeon Sulfolobus solfataricus in response to the carbon source L-fucose versus D-glucose. Mol. Microbiol. 2016, 102, 882-908. [CrossRef] [PubMed]

63. Siebers, B.; Tjaden, B.; Michalke, K.; Do, C.; Ahmed, H.; Zaparty, M.; Gordon, P.; Sensen, C.W.; Zibat, A.; Klenk, H.-P.; et al. Reconstruction of the central carbohydrate metabolism of Thermoproteus tenax by use of genomic and biochemical data. J. Bacteriol. 2004, 186, 2179-2194. [CrossRef] [PubMed]

64. Wolterink-van Loo, S.; van Eerde, A.; Siemerink, M.A.J.; Akerboom, J.; Dijkstra, B.W.; van der Oost, J. Biochemical and structural exploration of the catalytic capacity of Sulfolobus KDG aldolases. Biochem. J. 2007, 403, 421-430. [CrossRef]

65. Pauluhn, A.; Ahmed, H.; Lorentzen, E.; Buchinger, S.; Schomburg, D.; Siebers, B.; Pohl, E. Crystal structure and stereochemical studies of $\mathrm{KD}(\mathrm{P}) \mathrm{G}$ aldolase from Thermoproteus tenax. Proteins 2008, 72, 35-43. [CrossRef] [PubMed]

66. Khersonsky, O.; Roodveldt, C.; Tawfik, D.S. Enzyme promiscuity: Evolutionary and mechanistic aspects. Curr. Opin. Chem. Biol. 2006, 10, 498-508. [CrossRef] [PubMed]

67. Van der Oost, J.; Wolterink-Van Loo, S.; Siemerink, M.A.J.; Perrakis, G.; Kaper, T.; Kengen, S.W.M. Improving low-temperature activity of Sulfolobus acidocaldarius 2-keto-3-deoxygluconate aldolase. Archaea 2009, 2, 233-239. [CrossRef]

68. Royer, S.F.; Haslett, L.; Crennell, S.J.; Hough, D.W.; Danson, M.J.; Bull, S.D. Structurally informed site-directed mutagenesis of a stereochemically promiscuous aldolase to afford stereochemically complementary biocatalysts. J. Am. Chem. Soc. 2010, 132, 11753-11758. [CrossRef]

69. Tästensen, J.-B.; Johnsen, U.; Reinhartdt, A.; Ortjohjann, M.; Schönheit, P. D-Galactose catabolism in archaea: Operation of the DeLey-Doudoroff pathway in Haloferax volcanii. FEMS Microbiol. Lett. 2020, 367, fnaa029. [CrossRef] 
70. Kenney, K.L.; Smith, W.A.; Gresham, G.L.; Westover, T.L. Understanding biomass feedstock variability. Biofuels 2013, 4, 111-127. [CrossRef]

71. Aden, A.; Ruth, M.; Ibsen, K.; Jechura, J.; Neeves, K.; Sheehan, J.; Wallace, B. Lignocellulosic Biomass to Ethanol Process Design and Economics Utilizing Co-Current Dilute Acid Prehydrolysis and Enzymatic Hydrolysis for Corn Stover; National Renewable Energy Lab.: Golden, CO, USA, 2002.

72. Kobayashi, H.; Fukuoka, A. Synthesis and utilisation of sugar compounds derived from lignocellulosic biomass. Green Chem. 2013, 15, 1740-1763. [CrossRef]

73. McMillan, J.D. Xylose Fermentation to Ethanol: A Review; National Renewable Energy Lab.: Golden, CO, USA, 1993.

74. Moysés, D.N.; Reis, V.C.B.; de Almeida, J.R.M.; de Moraes, L.M.P.; Torres, F.A.G. Xylose fermentation by Saccharomyces cerevisiae: Challenges and prospects. Int. J. Mol. Sci. 2016, 17, 207. [CrossRef] [PubMed]

75. Oreb, M.; Dietz, H.; Farwick, A.; Boles, E. Novel strategies to improve co-fermentation of pentoses with D-glucose by recombinant yeast strains in lignocellulosic hydrolysates. Bioengineering 2012, 3, 347-351. [CrossRef] [PubMed]

76. Weimberg, R. Pentose oxidation by Pseudomonas fragi. J. Biol. Chem. 1961, 236, 629-635. [PubMed]

77. Dahms, S.A. 3-Deoxy-D-pentulosonic acid aldolase and its role in a new pathway of D-xylose degradation. Biochem. Biophys. Res. Commun. 1974, 60, 1433-1439. [CrossRef]

78. Watanabe, S.; Kodak, T.; Makino, K. Cloning, expression, and characterization of bacterial L-arabinose 1-dehydrogenase involved in an alternative pathway of L-arabinose metabolism. J. Biol. Chem. 2006, 281, 2612-2623. [CrossRef]

79. Radek, A.; Krumbach, K.; Gätgens, J.; Wendisch, V.F.; Wiechert, W.; Bott, M.; Noack, S.; Marienhagen, J. Engineering of Corynebacterium glutamicum for minimized carbon loss during utilization of D-xylose containing substrates. J. Biotechnol. 2014, 192, 156-160. [CrossRef]

80. Salusjärvi, L.; Toivari, M.; Vehkomäki, M.L.; Koivistoinen, O.; Mojzita, D.; Niemelä, K.; Penttilä, M.; Ruohonen, L. Production of ethylene glycol or glycolic acid from D-xylose in Saccharomyces cerevisiae. Appl. Microbiol. Biotechnol. 2017, 101, 8151-8163. [CrossRef]

81. Wasserstrom, L.; Portugal-Nunes, D.; Almqvist, H.; Sandström, A.G.; Lidén, G.; Gorwa-Grauslund, M.F. Exploring D -xylose oxidation in Saccharomyces cerevisiae through the Weimberg pathway. AMB Express 2018, 8, 33. [CrossRef]

82. Toivari, M.; Nygård, Y.; Kumpula, E.P.; Vehkomäki, M.L.; Benčina, M.; Valkonen, M.; Maaheimo, H.; Andberg, M.; Koivula, A.; Ruohonen, L.; et al. Metabolic engineering of Saccharomyces cerevisiae for bioconversion of D-xylose to D-xylonate. Metab. Eng. 2012, 14, 427-436. [CrossRef]

83. Nygård, Y.; Maaheimo, H.; Mojzita, D.; Toivari, M.; Wiebe, M.; Resnekov, O.; Pesce, C.G.; Ruohonen, L.; Penttilä, M. Single cell and in vivo analyses elucidate the effect of xylC lactonase during production of D-xylonate in Saccharomyces cerevisiae. Metab. Eng. 2014, 25, 238-247. [CrossRef]

84. Choi, S.Y.; Kim, W.J.; Yu, S.J.; Park, S.J.; Im, S.G.; Lee, S.Y. Engineering the xylose-catabolizing Dahms pathway for production of poly(D-lactate-co-glycolate) and poly(D-2-hydroxybutyrate) in Escherichia coli. Microb. Biotechnol. 2017, 10, 1353-1364. [CrossRef]

85. Boer, H.; Andberg, M.; Pylkkänen, R.; Maaheimo, H.; Kolvula, A. In vitro reconstitution and characterisation of the oxidative D-xylose pathway for production of organic acids and alcohols. AMB Express 2019, 9, 48. [CrossRef] [PubMed]

86. Borgström, C.; Wasserstrom, L.; Almqvist, H.; Broberg, K.; Klein, B.; Noack, S.; Lidén, G.; Gorwa-Grausland, M.F. Identification of modifications procuring growth on xylose of recombinant Saccharomyces cerevisae strains carrying the Weimberg pathway. Metab. Eng. 2019, 55, 1-11. [CrossRef]

87. Halmschlag, B.; Hoffmann, K.; Hanke, R.; Puytri, S.; Fukusaki, E.; Büchs, J.; Blank, L. Comparison of isomerase and Weimberg pathway for $\gamma$-PGA production from xylose by engineered Bacillus Subtilus. Front. Bioeng. Biotechnol. 2020, 7, 476. [CrossRef] [PubMed]

88. Meijnen, J.-P.; de Winde, J.H.; Ruijssenaars, H.J. Establishment of oxidative D-xylose metabolism in Pseudomonas putida S12. Appl. Environ. Microbiol. 2009, 75, 2784-2791. [CrossRef]

89. Bator, I.; Wittgens, A.; Rosenau, F.; Tiso, T.; Blank, L.M. Comparison of three xylose pathways in Pseudomonas putida KT2440 for the synthesis of valuable products. Front. Bioeng. Biotechnol. 2020, 7, 480. [CrossRef]

90. Van de Werken, H.J.G.; Brouns, S.J.J.; van der Oost, J. Pentose metabolism in archaea. In Archaea: New Models for Prokaryotic Biology; Blum, P., Ed.; Caister Academic Press: Norfolk, UK, 2008; pp. 71-94. 
91. Nunn, C.E.M.; Johnsen, U.; Schönheit, P.; Fuhrer, T.; Sauer, U.; Hough, D.W.; Danson, M.J. Metabolism of pentose sugars in the hyperthermophilic archaea Sulfolobus solfataricus and Sulfolobus acidocaldarius. J. Biol. Chem. 2010, 285, 33701-33709. [CrossRef] [PubMed]

92. Johnsen, U.; Sutter, J.M.; Zaiß, H.; Schönheit, P. L-Arabinose degradation pathway in the haloarchaeon Haloferax volcanii involves a novel type of L-arabinose dehydrogenase. Extremophiles 2013, 17, 897-909. [CrossRef] [PubMed]

93. Watanabe, S.; Kodaki, T.; Makino, K. A novel $\alpha$-ketoglutaric semialdehyde dehydrogenase: Evolutionary insight into an alternative pathway of bacterial L-arabinose metabolism. J. Biol. Chem. 2006, 281, 28876-28888. [CrossRef]

94. Watanabe, S.; Fukumori, F.; Watanabe, Y. Substrate and metabolic promiscuities of D-altronate dehydratase family proteins involved in non-phosphorylative D-arabinose, sugar acid, L-galactose and L-fucose pathways from bacteria. Mol. Microbiol. 2019, 112, 147-165. [CrossRef]

95. Watanabe, S.; Fukumori, F.; Nishiwaki, H.; Sakurai, Y.; Tajima, K.; Watanabe, Y. Novel non-phosphorylative pathway of pentose metabolism from bacteria. Sci. Rep. 2019, 9, 155. [CrossRef]

96. Lachaux, C.; Frazao, C.J.R.; Kraußer, F.; Morin, N.; Walther, T.; François, J.M. A new synthetic pathway for the bioproduction of glycolic acid from lignocellulosic sugars aimed at maximal carbon conservation. Front. Bioeng. Biotechnol. 2019, 7. [CrossRef]

97. Kim, S.M.; Paek, K.H.; Lee, S.B. Characterization of NADP+-specific L-rhamnose dehydrogenase from the thermoacidophilic Archaeon Thermoplasma acidophilum. Extremophiles 2012, 16, 447-454. [CrossRef]

98. Baldomà, L.; Aguilar, J. Metabolism of L-fucose and L-rhamnose in Escherichia coli: Aerobic-anaerobic regulation of L-lactaldehyde dissimilation. J. Bacteriol. 1988, 170, 416-421. [CrossRef] [PubMed]

99. Twerdochlib, A.L.; Pedrosa, F.O.; Funayama, S.; Rigo, L.U. L-Rhamnose metabolism in Pichia stipitis and Debaryomyces polymorphus. Can. J. Microbiol. 1994, 40, 896-902. [CrossRef]

100. Liu, B.; Zhang, Y.; Zhang, X.; Yan, C.; Zhang, Y.; Xu, X.; Zhang, W. Discovery of a rhamnose utilization pathway and rhamnose-inducible promoters in Pichia pastoris. Sci. Rep. 2016, 6, 27352. [CrossRef]

101. Khosravi, C.; Kun, R.S.; Visser, J.; Aguilar-Pontes, M.V.; de Vries, R.P.; Battaglia, E. In vivo functional analysis of L-rhamnose metabolic pathway in Aspergillus niger: A tool to identify the potential inducer of RhaR. BMC Microbiol. 2017, 17, 214. [CrossRef]

102. Boronat, A.; Aguilar, J. Metabolism of L-fucose and L-rhamnose in Escherichia coli: Differences in induction of propanediol oxidoreductase. J. Bacteriol. 1981, 147, 181-185. [CrossRef]

103. Rigo, L.U.; Marechal, L.R.; Vieira, M.M.; Viega, L.A. Oxidative pathway for L-rhamnose degradation in Pullularia pullulans. Can. J. Microbiol. 1985, 31, 817-822. [CrossRef]

104. Reinhardt, A.; Fohnen, U.; Schönheit, P. L-Rhamnose catabolism in archaea. Mol. Microbiol. 2019, 111, 1093-1108. [CrossRef]

105. Chen, Z.; Xu, W.; Zhang, W.; Zhang, T.; Jiang, B.; Mu, W. Characterization of a thermostable recombinant L-rhamnose isomerase from Caldicellulosiruptor obsdiansis OB47 and its application for the production of L-fructose and L-rhamnulose. J. Sci. Food Agric. 2018, 98, 2184-2193. [CrossRef] [PubMed]

106. Wagstaff, B.A.; Rejezk, M.; Kuhaudomlarp, S.; Hill, L.; Mascia, I.; Nepogodiev, S.A.; Dorfmueller, H.C.; Field, R.A. Discovery of an RmlC/Dfusion protein in the microalga Pyrmnesium parvum and its implications for NDP-ß-1-rhamnose biosynthesis in microalgae. J. Biol. Chem. 2019, 294, 9172-9185. [CrossRef] [PubMed]

107. Koivistoinen, O.M.; Arvas, M.; Headman, J.R.; Andberg, M.; Penttilä, M.; Jeffries, T.W.; Richard, P. Characterisation of the gene cluster for L-rhamnose catabolism in the yeast Scheffersomyces (Pichia) stipites. Gene 2012, 492, 177-185. [CrossRef] [PubMed]

108. Pacheco, A.R.; Munera, D.; Waldor, M.K.; Sperandio, V.; Ritchie, J.M. Fucose sensing regulates bacterial intestinal colonization. Nature 2012, 492, 113-117. [CrossRef]

109. Vanhooren, P.T.; Vandamme, E.J. L-Fucose: Occurrence, physiological role, chemical, enzymatic and microbial synthesis. J. Chem. Technol. Biotechnol. 1999, 74, 479-497. [CrossRef]

110. Hugdahl, M.B.; Beery, J.T.; Doyle, M.P. Chemotactic behavior of Campylobacter jejuni. Infect. Immun. 1998, 56, 1560-1566. [CrossRef]

111. Hooper, L.V.; Xu, J.; Falk, P.G.; Midtvedt, T.; Gordon, J.I. A molecular sensor that allows a gut commensal to control its nutrient foundation in a competitive ecosystem. Proc. Natl. Acad. Sci. USA 1999, 96, 9833-9838. [CrossRef] 
112. Cocks, G.T.; Aguilar, T.; Lin, E.C.C. Evolution of L-1, 2-propanediol catabolism in Escherichia coli by recruitment of enzymes for L-fucose and L-lactate metabolism. J. Bacteriol. 1974, 118, 83-88. [CrossRef]

113. Liu, J.-J.; Lee, J.W.; Yun, E.J.; Jung, S.-M.; Seo, J.-H.; Jin, Y.-S. L-Fucose production by engineered Escherichia coli. Biotechnol. Bioeng. 2019, 116, 904-911. [CrossRef]

114. Stahl, M.; Friis, L.M.; Nothaft, H.; Liu, X.; Li, J.; Szymanski, C.M.; Stintzi, A. L-Fucose utilization provides Campylobacter jejuni with a competitive advantage. Proc. Natl. Acad. Sci. USA 2011, 108, 7194-7199. [CrossRef]

115. Watanabe, S. Characterization of L-2-keto-3-deoxyfuconate aldolases in a nonphosphorylating L-fucose metabolism pathway in anaerobic bacteria. J. Biol. Chem. 2020, 295, 1338-1349. [CrossRef]

116. Sharma, V.; Ichikawa, M.; Freeze, H.H. Mannose metabolism: More than meets the eye. Biochem. Biophys. Res. Commun. 2014, 453, 220-228. [CrossRef] [PubMed]

117. Maruyama, Y.; Nakajima, T.; Ichishima, E. A 1,2- $\alpha$-D-mannosidase from a Bacillus sp.: Purification, characterization, and mode of action. Carbohydr. Res. 1994, 251, 89-98. [CrossRef]

118. Duffaud, G.D.; McCutchen, C.M.; Leduc, P.; Parker, K.N.; Kelly, R.M. Purification and characterization of extremely thermostable $\beta$-mannanase, $\beta$-mannosidase, and $\alpha$-galactosidase from the hyperthermophilic eubacterium Thermotoga neapolitana 5068. Appl. Environ. Microbiol. 1997, 63, 169-177. [CrossRef] [PubMed]

119. Nakajima, M.; Fushinobu, S.; Imamura, H.; Shoun, H.; Wakagi, T. Crystallization and preliminary X-ray analysis of cytosolic $\alpha$-mannosidase from Thermotoga maritima. Acta Crystallogr. Sect. F Struct. Biol. Cryst. Commun. 2006, 62, 104-105. [CrossRef] [PubMed]

120. Angelov, A.; Putyrski, M.; Liebl, W. Molecular and biochemical characterization of $\alpha$-glucosidase and $\alpha$-mannosidase and their clustered genes from the thermoacidophilic archaeon Picrophilus Torridus. J. Bacteriol. 2006, 188, 7123-7131. [CrossRef] [PubMed]

121. Numao, S.; He, S.; Evjen, G.; Howard, S.; Tollersrud, O.K.; Withers, S.G. Identification of Asp197 as the catalytic nucleophile in the family $38 \alpha$-mannosidase from bovine kidney lysosomes. FEBS Lett. 2000, 484, 175-178. [CrossRef]

122. Gibbs, M.D.; Elinder, A.U.; Reeves, R.A.; Bergquist, P.L. Sequencing, cloning and expression of a $\beta$-1,4-mannanase gene, man A, from the extremely thermophilic anaerobic bacterium, Caldicellulosiruptor Rt8B.4. FEMS Microbiol. Lett. 1996, 141, 37-43. [CrossRef]

123. Sunna, A.; Gibbs, M.D.; Chin, C.W.J.; Nelson, P.J.; Bergquist, P.L. A gene encoding a novel multidomain $\beta-1,4-$ mannanase from Caldibacillus cellulovorans and action of the recombinant enzyme on kraft pulp. Appl. Environ. Microbiol. 2000, 66, 664-670. [CrossRef]

124. Sunna, A. Modular organisation and functional analysis of dissected modular $\beta$-mannanase CsMan26 from Caldicellulosiruptor Rt8B.4. Appl. Microbiol. Biotechnol. 2010, 86, 189-200. [CrossRef]

125. Szymona, M.; Doudoroff, M. Carbohydrate metabolism in Rhodopseudomonas Spheroides. J. Gen. Microbiol. 1960, 22, 167-183. [CrossRef] [PubMed]

126. Nguyen, Q.A.; Cho, E.; Trinh, L.T.P.; Jeong, J.-S.; Bae, H.-J. Development of an integrated process to produce D-mannose and bioethanol from coffee residue waste. Bioresour. Technol. 2017, 244, 1039-1048. [CrossRef] [PubMed]

127. Saburi, W.; Sato, S.; Hashiguchi, S.; Muto, H.; Lizuka, T.; Mori, H. Enzymatic characteristics of D-mannose 2-epimerase, a new member of the acylglucosamine 2-epimerase superfamily. Appl. Microbiol. Biotechnol. 2019, 103, 6559-6570. [CrossRef] [PubMed]

128. Nishiya, Y.; Tamura, N.; Tamura, T. Analysis of bacterial glucose dehydrogenase homologs from thermoacidophilic archaeon Thermoplasma acidophilum: Finding and characterization of aldohexose dehydrogenase. Biosci. Biotechnol. Biochem. 2004, 68, 2451-2456. [CrossRef]

129. Yasutake, Y.; Nishiya, Y.; Tamura, N.; Tamura, T. Structural Insights into unique substrate selectivity of Thermoplasma acidophilum D-aldohexose dehydrogenase. J. Mol. Biol. 2007, 367, 1034-1046. [CrossRef]

130. Kopp, D.; Willows, R.D.; Sunna, A. Cell-free enzymatic conversion of spent coffee grounds into the platform chemical lactic acid. Front. Bioeng. Biotechnol. 2019, 7, 389. [CrossRef]

131. Krause-Jensen, D.; Duarte, C. Substantial role of macroalgae in marine carbon sequestration. Nat. Geosci. 2016, 9, 737-742. [CrossRef]

132. Kamke, J.; Sczyrba, A.; Ivanova, N.; Schwientek, P.; Rinke, C.; Mavromatis, K.; Woyke, T.; Hentschel, U. Single-cell genomics reveals complex carbohydrate degradation patterns in poribacterial symbionts of marine sponges. ISME J. 2013, 7, 2287-2300. [CrossRef] 
133. Reisky, L.; Préchoux, A.; Zühlke, M.-K.; Bäumgen, M.; Robb, C.S.; Gerlach, N.; Roret, T.; Stanetty, C.; Larocque, R.; Michel, G.; et al. A marine bacterial enzymatic cascade degrades the algal polysaccharide ulvan. Nat. Chem. Biol. 2019, 15, 803-812. [CrossRef]

134. Sichert, A.; Corzett, C.H.; Schechter, M.S.; Unfried, F.; Markert, S.; Becher, D.; Fernandez-Guerra, A.; Liebeke, M.; Schweder, T.; Polz, M.F.; et al. Verrucomicrobia use hundreds of enzymes to digest the algal polysaccharide fucoidan. Nat. Microbiol. 2020, 5, 1026-1039. [CrossRef]

135. Cuskin, F.; Lowe, E.C. Glyan degradation writ large in the ocean. Nat. Microbiol. 2020, 5, 980-981. [CrossRef]

136. Ndeh, D.; Rogowski, A.; Cartmell, A.; Luis, A.S.; Baslé, A.; Gray, J.; Venditto, I.; Briggs, J.; Zhang, X.; Labourel, A.; et al. Complex pectin metabolism by gut bacteria reveals novel catalytic functions. Nature 2017, 544, 65-70. [CrossRef] [PubMed]

Publisher's Note: MDPI stays neutral with regard to jurisdictional claims in published maps and institutional affiliations.

(C) 2020 by the authors. Licensee MDPI, Basel, Switzerland. This article is an open access article distributed under the terms and conditions of the Creative Commons Attribution (CC BY) license (http://creativecommons.org/licenses/by/4.0/). 